\title{
LAS BASES SOCIALES Y POLÍTICAS DE LA ABSTENCIÓN EN LAS ELECCIONES GENERALES ESPAÑOLAS: RECURSOS INDIVIDUALES, MOVILIZACIÓN ESTRATÉGICA E INSTITUCIONES ELECTORALES *
}

\author{
Carles Boix ${ }^{* *}$ y Clara Riba ${ }^{* * *}$
}

\footnotetext{
* Agradecemos la ayuda financiera del Centro de Investigaciones Sociológicas y del Centre per a la Recerca en Economia Internacional (CREI) de la Universitat Pompeu Fabra.

** Profesor en los Departmentos de Ciencia Política y de Economía de Ohio State University. Dirección: Department of Political Science, 2176 Derby Hall, The Ohio State University, Columbus, OH 43210-1373, USA. E-mail: boix.1@ osu.edu.

*** Profesora en el Departamento de Economía de la Universitat Pompeu Fabra, Barcelona. Dirección: Departamento de Economía, Universitat Pompeu Fabra, Barcelona 08005. E-mail: criba@econ.upf.es.
} 


\section{SUMARIO}

Este informe de investigación examina los factores sociales y políticos que han determinado el nivel y variabilidad de la abstención electoral en las elecciones generales españolas. Extendiendo los modelos de carácter psicológico y sociológico que se han empleado (con éxito relativo) para explicar la abstención española, este estudio muestra que el nivel de participación en las elecciones generales depende en buena medida de factores estrictamente políticos: la satisfacción global del electorado con la situación política del país, la implantación y capacidad de movilización de los partidos políticos, el nivel de asociacionismo y 'capital social', el grado de competitividad electoral en cada área geográfica y los cálculos estratégicos que los electores realizan en función del tamaño de las circunscripciones electorales y de las distorsiones a la representación que impone la ley electoral. El informe emplea datos

individuales, procedentes de las encuestas postelectorales del CIS, y utiliza regresiones multivariantes no lineales, aplicadas a muestras agregadas en panel.

Palabras claves: Participación electoral, Política española, Instituciones electorales

JEL: D72 


\section{INTRODUCCIÓN. EL ESTUDIO DE LA ABSTENCIÓN EN ESPAÑA.}

La participación en el proceso electoral (y en la vida política en general) constituye uno de los elementos esenciales de la vida democrática. Desde un punto de vista normativo, la literatura ha identificado la consecución de una participación política y electoral elevada como uno de los requisitos necesarios para conferir legitimidad y dotar de eficacia al sistema político. Desde un punto de vista empírico, la investigación politológica reciente ha mostrado que el nivel de participación electoral constituye una variable importante para explicar variaciones significativas tanto en los resultados electorales (Nagel 1987; Rosenstone y Hansen 1993; para España y, en particular, Cataluña, véase Riba 1995) como en la naturaleza de las políticas gubernamentales (Meltzer y Richards 1981; Pampel y Williamson 1988; Hicks y Swank 1992). En sistemas políticos en los que los electores se hallan fuertemente 'anclados' en ciertas posiciones ideológicas o lealtades partidistas, es muy probable que la abstención constituya un elemento clave para explicar cambios en la distribución de votos en elecciones consecutivas. Los votantes tradicionalmente cercanos a un partido o bloque ideológico determinado raramente deciden votar por un candidato o lista electoral que no constituya su primera preferencia. Aquellos votantes descontentos con la campaña o gestión gubernamental del partido con el que simpatizan castigan a este último mediante la abstención. Por la misma razón, la movilización de toda la base de sus electores potenciales constituye una de las claves de la victoria electoral de un partido político.

Desde el restablecimiento de la democracia en España, el grado de participación electoral ha variado notablemente en función del momento en que se celebraron las elecciones, el tipo de convocatoria y el área geográfica. A la par con la creciente consolidación de la democracia española y la acumulación de los datos provinientes de una serie ya dilatada de elecciones, la ciencia política española ha generado varios estudios sobre la abstención electoral en nuestro país (y, de manera general, sobre los niveles de participación política) de índole diversa. En términos generales, los estudios realizados hasta el momento han propuesto explicaciones de índole psicológica y sociológica para dar cuenta de la variación temporal, 
geográfica y social de la abstención en España. ${ }^{1}$

En las explicaciones psicológicas, la abstención se ha correlacionado con la existencia de un conjunto de actitudes individuales (hacia el sistema político) tales como desinterés, apatía y, en general, ‘desafección' hacia la esfera política. En los modelos sociológicos, la variación de la abstención se ha atribuido, a su vez, a diferencias en factores estructurales, tales como la edad, hábitat, clase social y renta económica, que, al afectar los recursos personales (y, en parte, el grado en que las decisiones políticas afectan el bienestar individual) de cada elector, modifican la probabilidad de que cada elector vote. Aunque estos modelos muestran una cierta validez para explicar el abstencionismo en las elecciones norteamericanas, ${ }^{2}$ su capacidad explicativa ha sido menor para el caso español. Tres son los problemas que se suscitan en estos estudios. En primer lugar, los factores estructurales, tales como estructura productiva, ingresos o urbanización, que desempeñaron un cierto papel explicativo para las primeras elecciones democráticas, parecen haber dejado de afectar el comportamiento abstencionista desde finales de la década de los ochenta (Justel 1990). En segundo lugar, los modelos sociológicos son incapaces, por definición, de dar cuenta tanto de las diferencias de participación en comicios de distinto rango como de las fluctuaciones temporales en elecciones del mismo nivel (por ejemplo, elecciones generales). Finalmente, los estudios sobre abstención se han llevado a cabo en España mediante técnicas multivariantes lineales, que introducen un grave sesgo en los resultados explicativos de variables dependientes dicotómicas (como es el caso de votar o no). ${ }^{3}$

A fin de resolver los problemas de explicaciones puramente sociológicas, la abstención ha empezado a ser concebida entre algunos autores como un fenómeno determinado por factores de naturaleza política: el grado de identificación de los ciudadanos con las instituciones políticas (en el caso español, por ejemplo, la diferencia entre elecciones estatales o autonómicas -- véase Font (1995)); el

\footnotetext{
${ }^{1}$ La aportación fundamental en este caso es la de Justel (1990, 1995). Véase también Montero (1984, 1986).

${ }^{2}$ Véase el análisis de Rosenstone y Hansen (1993).

${ }^{3}$ Véase en este sentido King (1990).
} 
grado de eficacia interna y externa de los electores; y los cálculos estratégicos de los votantes (Riba 1995). ${ }^{4}$ No obstante, el análisis de la abstención electoral española como resultado de factores políticos se halla en un estado incipiente tanto desde un punto teórico como desde una perspectiva empírica. Los estudios existentes no han desarrollado la estructura causal que define la relación entre las estrategias de los candidatos políticos y el grado de movilización electoral. Asimismo, no se ha llevado una investigación sistemática de esta aproximación teórica, con datos individuales y técnicas de regresión no lineal, para todas las elecciones generales.

A fin de remediar estos problemas, este estudio examina de manera sistemática los factores conducentes a la decisión de abstenerse en las elecciones generales españolas de 1982, 1989, 1993 y 1996. Con tal fin, este estudio explora de forma exhaustiva tanto el impacto de variables psicológicas y sociales individuales y agregadas como el efecto de factores estrictamente políticos e institucionales. Asimismo, al objeto de eliminar los problemas metodológicos de estudios anteriores, este trabajo realiza estimaciones de modelos de regresión logística, apropiados para variables dicotómicas tales como la decisión de votar o de abstenerse. Este informe se organiza de la siguiente manera. En la sección 2 se describe brevemente el conjunto de modelos que la literatura ha barajado para explicar el fenómeno de la abstención. En la sección 3 se presenta datos agregados sobre el fenómeno de la abstención en España desde el restablecimiento de la democracia. En la sección 4 se describe la metodología y la muestra empleada. En la secciones 5 y 6 se presentan los resultados y se incluyen simulaciones de los resultados obtenidos. La sección 7 presenta las conclusiones del informe.

\section{LAS CAUSAS DE LA PARTICIPACIÓN ELECTORAL.}

Aunque el número de factores que se han propuesto para explicar variaciones en el grado de participación electoral es considerable, es posible agruparlos en torno a tres explicaciones centrales: los recursos de los electores, la movilización estratégica llevada a cabo por las élites políticas, y las

\footnotetext{
${ }^{4}$ A esta literatura hay que añadir la relevancia que la variables 'capital social' parece tener en el ámbito de participación no electoral (Montero y Torcal 1997).
} 
instituciones político-electorales que afectan las decisiones y movilización de los electores. Aunque estas tres perspectivas se relacionan entre sí, en la medida en que afectan los cálculos que los individuos realizan sobre los costes y beneficios que les reporta la decisión de participar, es conveniente examinarlas por separado.

Al examinar las causas de la abstención es apropiado concebir el acto de votar como el último paso en un proceso en el que cada individuo, en función de su nivel de motivación e interés en el proceso electoral, y tras considerar tanto el grado en que su acción es capaz de influir en las decisiones colectivas como los costes que le reporta votar, juzga mediante qué tipo de acciones y con qué grado de intensidad resultado adecuado participar en la esfera política y en la toma de decisiones colectivas. (Aunque este enfoque se acerca al proceso de modelar la decisón de votar como resultado de realizar un cálculo estricto de costes y beneficios, nótese que la formulación que empleamos es menos estricta que una aproximación puramente racional. Nuestra formulación nos permite escapar, en cierta medida, del problema (irresuelto todavía en la literatura actual) de la paradoja del voto. ${ }^{5}$

La motivación política de cada individuo, el interés que éste muestra por la política y los costes y beneficios que le reporta la acción de votar vienen modificados, en primer lugar, por los recursos de que dispone. Por recursos se entiende los elementos que caracterizan a los electores y que estos emplean en el proceso de decisión y de participación política: conocimiento y educación, medios materiales y tiempo. Dado que la decisión de participar requiere una inversión de recursos, es decir, un cierto coste, se ha tendido a concluir que aquellas personas con mayor tiempo, dinero e información tienen una mayor propensión a participar. El coste relativo de votar disminuye al tener más recursos. Asimismo, se presume que aquellos que tienen una mayor educación y experiencia tienden a sentirse más eficaces desde un punto de vista político y, en consecuencia, tienden a participar con más frecuencia. Una de las primeras formulaciones clásicas, por Verba y Nie (1972), relacionó el grado de participación con el nivel de educación, ingresos y variables ocupacionales. El problema fundamental de este aproximación teórica es su incapacidad en explicar diferencias considerables en participación electoral entre países así como entre

\footnotetext{
${ }^{5}$ Sobre la paradoja del voto, véase una discusión reciente en Aldrich (1997).
} 
elecciones diferentes en un mismo país. Numerosos estudios empíricos muestran que las diferencias en participación debidas a diferencias en educación y renta son menores que las diferencias en participación en países diferentes. En otras palabras, los países con mayor participación electoral no necesariamente tienen un nivel de renta y educación mayor que los países con un alto grado de abstención.

Dado el carácter limitado de la teoría de recursos, la literatura ha considerado el grado en que élites y organizaciones políticas movilizan a los electores (Rosenstone y Hansen 1993; Verba et al. 1995). Esta segunda aproximación, que ha recibido la denominación de movilización estratégica, examina la medida en que el proceso desencadenado por las élites políticas (candidatos, medios de comunicación, organizaciones intermedias) para a concienciar a los electores sobre la necesidad e importancia de su participación reduce la abstención. De acuerdo con esta explicación, a mayor grado de movilización, los costos que conlleva la recogida de información para tomar decisiones disminuyen. Asimismo, los electores cuentan con la seguridad que otros electores participarán en el proceso electoral y, al reforzar la eficacia última del voto de los electores, esta seguridad incrementa los incentivos ligados al proceso de participación. Aunque el concepto de movilización estratégica aumenta la varianza explicada en el grado de abstención, el concepto de movilización no resuelve por completo los problemas empíricos existentes en el modelo de recursos. Rosenstone y Hansen (1993) muestran que la actividad de los candidatos incrementa el grado de participación electoral en los Estados Unidos. No obstante, Franklin (1996) concluye que estos efectos son mínimos en Europa hoy en día.

El concepto de movilización estratégica subraya la necesidad de considerar el contexto social y político en el que cada elector decide votar (o abstenerse). No es extraño, por tanto, que la literatura haya complementado esta aproximación con una referencia al papel que desempeñan las instituciones y contextos electorales en que participan los electores (Crewe 1981; Powell 1980; Jackman 1987; Franklin 1996). Al elevar considerablemente el coste de votar o reducir los beneficios que cabe esperar del acto de votar, las instituciones y reglas electorales afectan directamente la probabilidad de participación de los electores. Son varios los mecanismos institucionales barajados por la literatura. Aquellos sistemas electorales que dificultan la representación de minorías políticas, mediante el establecimiento de barreras legales, la utilización de circunscripciones de tamaño reducido y la utilización de fórmulas de asignación 
poco proporcionales, incrementan la abstención. El establecimiento de mecanismos fáciles y extensos para votar, tales como un censo electoral automático o el voto por correo, elevan la participación. La relevancia de las elecciones, que depende del grado de soberanía política y competencias del órgano que se vota, modifica la motivación de los electorales. Finalmente, la participación electoral depende del grado de competitividad de las elecciones: cuando más equilibrados se hallen los partidos políticos entre sí y más incierto sea el resultado, más proclive será el votante a acudir a las urnas.

\section{LA ABSTENCIÓN EN ESPAÑA: DATOS AGREGADOS.}

Previamente al análisis estadístico que constituye el objeto del este trabajo, es conveniente describir, a grandes rasgos, las características principales de la abstención española. En su conjunto, la participación en las elecciones generales españolas ha fluctuado en torno al 74 por ciento -- es decir, por debajo (en unos 6 puntos porcentuales) de la media de las democracias avanzadas, aunque claramente por encima de los niveles de participación en Estados Unidos y Suiza.

[Figura 1 aquí]

El grado de participación electoral varía considerablemente según el tipo de convocatoria electoral. Mientras que en las elecciones generales la media ha sido del 74 por ciento, en las elecciones locales ha sido del 65 por ciento y en las europeas del 61 por ciento (Figura 1). Estos diferenciales de participación se deben, en buena medida, a la importancia simbólica y material de las instituciones que se eligen en cada convocatoria y no se alejan de lo que constituye una pauta de comportamiento similar en otros países (Reif y Schmitt 1980; Reif 1985; van der Eijk et al 1996; Franklin 1996).

La abstención electoral muestra fluctuaciones temporales importantes en España. En las elecciones generales, la abstención ha oscilado entre un máximo del 32 por ciento en 1979 y un mínimo del 20,2 por ciento en 1982. Como muestra la figura 2 (y corrobora el análisis estadístico de las secciones 5 y 6), la fluctuación intertemporal en los niveles de abstención electoral se halla estrechamente relacionada con los juicios globales (de satisfacción) sobre la situación económica y política española: a mayor insatisfacción, menor es el grado de abstención -- con exclusión de la elección general de 1977. La movilización se produce, por tanto, en función del grado de crisis de eficacia gubernamental que perciben 
los electores.

Finalmente, la estructura de la abstención se ha modificado sustancialmente desde el restablecimiento de la democracia -- cuando menos a nivel agregado. En 1979, la participación electoral a nivel provincial varió entre un 42,2 por ciento en Orense y un 72,2 por ciento en Castellón. En 1993 la dispersión interprovincial se había reducido en más de la mitad, del 67,5 por ciento en Guipúzcoa en al 83 por ciento en Toledo. Como muestra la figura 3, en quince años se ha producido un acelerado proceso de convergencia hacia la media española: aquellas provincias con mayor abstención a finales de la década de los setenta son las que han aumentado en mayor medida su participación.

La estructura de los datos agregados de la abstención española contienen una lección importante. Cualquier explicación satisfactoria del fenómeno de la abstención exige desarrollar un modelo que, juntamente con los factores individuales que modifican la decisión de votar (y que constituyen el elemento central de las aportaciones que se han hecho en la literatura de factura doméstica sobre la abstención), incorpore variables institucionales y políticas, tales como las instituciones electorales, las políticas gubernamentales, el contexto social del elector y la movilización estratégica promovida por los partidos políticos.

\section{METODOLOGÍA.}

\subsection{Muestra analizada.}

La investigación de las causas de la abstención en la elecciones generales españolas se ha realizado mediante la explotación sistemática de las encuestas postelectorales realizadas por el Centro de Investigaciones Sociológicas en 1982, 1989, 1993 y $1996{ }^{6}$

La explotación de las encuestas postelectorales se ha llevado a cabo mediante la construcción de un panel conjunto de las encuestas. Para el panel en su conjunto y para cada año electoral por separado

\footnotetext{
${ }^{6}$ Las eleccioes de 1977, 1979 y 1986 se han excluido por dos razones. Por una parte, no existen matrices susceptibles de explotación estadística para las dos primeras elecciones democráticas. Por otra parte, hemos detectado problemas importantes en la codificación de los resultados de la encuesta postelectoral 1986, que hacen aconsejable no incluirla en el análisis.
} 
(así como para las encuestas de la primera época, 1982-89, y de la segunda época, 1993-96), se ha realizado la estimación, mediante un modelo logístico, de la probabilidad de que cada individuo vote o se abstenga.

\subsection{Variable dependiente.}

La abstención se ha definido de dos maneras alternativas:

- aquellos individuos que no votaron;

- aquellos individuos que no votaron con exclusión de los que quisieron hacerlo pero que, por razones técnicas (p.e. errores en el censo), no pudieron hacerlo.

Los resultados que se incluyen en este trabajo se basan en la primera medida. Las diferencias en resultados en función de cambios en la variable dependiente no difieren sustancialmente según la variable que se empleen.

La variable dependiente toma el valor de 1 si el individuo declara haberse abstenido y 0 si responde haber votado.

Es importante subrayar que la abstención declarada en las encuestas es sustancialmente menor que la abstención en las urnas. Por término medio, solamente un 13 por ciento de los encuestados declaran haberse abstenido. La abstención real es, tal como se desprende de los datos presentados en la sección 3, del 26 por ciento. En el análisis que sigue suponemos que la distribución de la abstención declarada no está sesgada respecto a la abstención real. Por esta razón empleamos en todo momento el término abstención. En un sentido estricto, no obstante, es necesario reconocer que nuestros resultados solamente son explicativos de la abstención admitida por los encuestados.

\subsection{Variables independientes.}

Para determinar las causas de la decisión de abstenerse, se han considerado las siguientes variables.

A. Variables que miden recursos individuales.

Estas variables incluyen: 


\section{A.1. Variables sociológicas individuales:}

- tamaño de la población en que vive el encuestado;

- nivel de educación;

- edad;

- sexo;

- variables ocupacionales dicotómicas indicando, para cada individuo: si trabaja o no; si es estudiante o no; si esta jubilado o no; y si su ocupación es ‘sus labores' o no;

- profesión que tiene (el encuestado o, en su defecto, el cabeza de familia), clasificado según las siguientes categorías: profesional con asalariados; empresario con asalariados; profesional sin asalariados; empresario autónomo agrícola; empresario auónomo industrial; empresario autónomo de servicios; directivo; cuadro medio; empleado de oficina; vendedor; capataz; personal subalterno; trabajador de la industria; trabajador de servicios; trabajador agrícola. (Para cada categoría se ha construido una variable dicotómica.)

A.2 Variables 'agregadas' (a nivel provincial) de carácter sociológico:

- nivel de asociacionismo, medido como número de asociaciones por cada 1.000 habitantes;

- renta provincial bruta y renta provincial disponible (después de transferencias) per cápita (en pesetas de 1982);

- nivel de transferencias públicas en la provincia de cada individuo; las transferencias públicas se estiman como la diferencia entre la renta provincial bruta per cápita (RPB) y la denominada "renta familiar disponible" per cápita (RFD) -- la "renta familiar disponible" es la suma de todos los salarios, rentas de capital, rentas sociales (tales como pensiones, etc.) y las transferencias netas menos las aportaciones a la Seguridad Social y los impuestos directos. ${ }^{7}$

- estructura productiva de la provincia, medida por el porcentaje de población activa en

\footnotetext{
${ }^{7}$ Se asume, por tanto, que la diferencia entre RPB y RFD muestra el nivel neto de transferencias del Estado, esto es, la forma en que los impuestos y el gasto social afectan a la renta final y corrigen las desigualdades iniciales. Este parámetro cumple su objetivo, no obstante, de una manera bastante rudimentaria ya que no mide ni los niveles de formación de capital fijo público y empleo público, ni el impacto que este último puede ejercer sobre la tasa de crecimiento de cada área.
} 
agricultura, industria y servicios;

- tasa de paro en cada provincia;

B. Variables de movilización política.

Estas variables incluyen:

- nivel de militancia política en la provincia de cada individuo, medido por el número de militantes del PSOE por cada 1.000 habitantes en 1989;

- grado de interés por la política;

- satisfacción con la situación económica y política actual y futura;

- autoubicación ideológica en el espacio izquierda-derecha;

- grado de seguimiento de la campaña electoral;

- valoración de los candidatos políticos principales;

- grado de moderación ideológica, medida por la desviación de la autoubicación ideológica

respecto a la media española (y también respecto a la mediana);

- distancia política del encuestado (en la escala izquierda-derecha) respecto a la ubicación

ideológica de AP/PDP/PP; distancia política respecto al PSOE; distancia política respecto al PCE;

- grado en que la campaña electoral sirve para conocer mejor a los líderes, informarse de los programas de los partidos y ver diferencias entre partidos;

- imagen después de la campaña electoral de González y de Aznar;

- imagen durante la campaña electoral del PP, del PSOE y de IU;

- situación política prospectiva;

- situación económica prospectiva;

- una variable para cada elección que indica el porcentaje de personas satisfechas con la situación política y económica en el país en el año previo a la celebración de las elecciones -- esta variable toma los valores de 5\% en $1982,17 \%$ en $1989,11 \%$ en 1993 y $12 \%$ en 1996.

\section{Variables político-institucionales.}

Estas variables incluyen:

- grado de competitividad electoral en la provincia de cada individuo, medido por la diferencia 
entre los dos partidos más votados en las elecciones anteriores;

- 'proporcionalidad' del sistema electoral de cada provincia; para determinar la medida en que el grado de proporcionalidad incentiva la participación (al reducir la llamada abstención por alienación).

La proporcionalidad del sistema electoral se mide mediante el cálculo de la barrera o umbral efectivo. La barrera o umbral efectivo de cada circunscripción electoral es: (a) el umbral 'medio' correspondiente a la magnitud del distrito si este umbral es superior al mínimo legal (el 3\% en España) que toda lista ha de obtener para participar en el proceso de asignación de escaños; (b) el mínimo legal cuando el 'umbral medio' es menor que aquel. Siguiendo la literatura al uso (Taagapera y Shugart 1989), el 'umbral medio' se calcula como el promedio del umbral máximo y el umbral mínimo. El umbral máximo, esto es, aquella proporción de votos por encima del cual el candidato se asegura por completo la obtención de un escaño, se estima mediante la fórmula:

$$
U \max =1 / M+1,
$$

donde $\mathrm{M}$ es el número de escaños en cada distrito. El umbral mínimo, esto es, la proporción de votos mínima que permite a un partido obtener un escaño si compite bajo condiciones óptimas (la oposición acude a las urnas completamente fragmentada), se calcula como:

$$
\operatorname{Umin}=1 /\left(M^{*} p\right)
$$

donde $p$ es el número de partidos. ${ }^{8}$

\subsection{Metodología empleada.}

Dado el carácter dicotómico de la variable dependiente, la explotación de la matriz se lleva a cabo mediante la aplicación de un model de regresión logística.

\section{RESULTADOS (I). RECURSOS INDIVIDUALES Y ESTRUCTURA SOCIOECONÓMICA.}

Las tablas 1 a 4 describen los resultados estadísticos obtenidos. En las tablas 1 y 2 se muestra el

\footnotetext{
${ }^{8}$ También se han empleados las siguientes variables: umbral mínimo, umbral máximo, número de escaños en la circunscripción.
} 
efecto que las variables de carácter sociológico tienen sobre la probabilidad de abstenerse. En las tablas 3 y 4 se procede a examinar el impacto de las variables políticas individuales e institucionales.

[Tabla 1 aquí]

La tabla 1 incluye un modelo inicial en el que se incluye aquellas tres variables para las que tenemos datos comparables para todo el período bajo análisis que definen los recursos de carácter individual de que dispone cada votante: edad, educación y situación laboral del individuo (definida por tres posibilidades: si trabaja o no, si está jubilado o no y si está clasificado como 'sus labores' o no). A estas variables se añade el tamaño del hábitat y el porcentaje de electores satisfechos con la situación política del país en el año anterior a las elecciones. La exclusión de esta última variable no afecta los resultados de las restantes variables.

En la tabla 1 se incluyen los resultados provenientes de la muestra completa (años 1982, 1989, 1993 y 1996) (columna 1) y de dos submuestras -- la que incluye los años 1982 y 1989 y la que incluye los años 1993 y 1996. Esta división, que también se emplea en las tablas siguientes, responde a las siguientes causas: el sistema de partidos y el grado de competitividad en las elecciones generales varía en ambos períodos (el primero se caracteriza por la hegemonía del PSOE y el segundo por una notable proximidad entre PSOE y PP); las variables ocupacionales (que se emplean en la tabla 2) se basan en clasificaciones que obedecen a criterios parcialmente diferentes en cada período; las variaciones que se dan en el rol de ciertas variables independientes se producen básicamente entre estos dos períodos (así, por ejemplo, el efecto del tamaño del hábitat cambia sustancialmente de 1982-89 a 1993-96).

[Tabla 2 aquí]

La tabla 2 extiende el modelo restringido de la tabla 1 mediante la incorporación de dos tipos de variables: las variables ocupacionales referentes a la categoría profesional y las variables socioeconómicas estructurales de cada provincia (porcentaje de paro, peso de los sectores agrícola, industrial y de servicios, renta per cápita y nivel de transferencias). Debido al hecho de que los criterios empleados para clasificar los encuestados según su ocupación cambiaron radicalmente en la encuesta postelectoral del CIS, no es posible realizar el análisis sobre la muestra completa. Por esta razón, la tabla 2 solamente incluye los resultados para el período 1982-89 en la columna 1 y para el período 1993-96 en 
la columna 2.

Dada la dificultad de interpretación de los coeficientes que se obtienen en estimaciones no lineales como la que empleamos, complementamos las tablas con simulaciones que muestran el impacto real que cada variable tiene por separado sobre la decisión de votar del individuo. Las simulaciones que llevamos a cabo fijan todas las variables de cada regresión en su media, excepto el factor cuyo efecto deseamos explorar.

[Figuras 4 y 5 aquí]

De acuerdo con los resultados de las tablas 1 y 2, la edad y la educación tienen un efecto significativo sobre la decisión de abstenerse. Los coeficientes son, además, estables con independencia de la especificación empleada (aunque, tal como indicamos después, el coeficiente de la educación cambia de signo una vez se incluye la variable 'interés en la campaña electoral' en la tabla 4). Tal como ha mostrado la literatura sobre participación en otros países, el grado de abstención se reduce con la edad. En la figura 4 simulamos el efecto que un cambio en la edad tiene sobre la probabilidad de votar. ${ }^{9}$ Una vez situamos las restantes variables en sus medias, ${ }^{10}$ es posible observar que, según los resultados de la muestra, la probabilidad de abstenerse se sitúa en torno al 21 por ciento entre personas de 18 años y se reduce al 5 por ciento entre los mayores de 80 años. ${ }^{11}$ El impacto de la edad sobre la decisión de votar se ha acentuado con el paso de tiempo. En el primer período de análisis, la diferencia en la probabilidad de votar entre personas de 18 y más de 75 años fue de 9 puntos. En el segundo período alcanzó los 22 puntos porcentuales.

Por su parte, un incremento en el nivel de educación incrementa la probabilidad de votar. No

\footnotetext{
${ }^{9}$ Las simulaciones de las figuras 4 a 11 emplean las regresiones de la tabla 3.

${ }^{10}$ Las medias son: tamaño del hábitat, 3,96; edad, 44,4; educación, 3,81; trabaja, 0,41; está jubilado, 0,17; sus labores, 0,24; número de asociaciones, 3,70; militantes del PSOE, 9,61; nivel de competitividad, 13,30; barrera efectiva, 8,76; interés por la campaña electoral, 3,05; distancia respecto a la media ideológica, 1,54.

${ }^{11}$ Los resultados apenas varían si se tiene en cuenta que a partir de los 65 años los electorales están, en su mayoría, de jubilados (condición que, de acuerdo con los resultados, incrementa marginalmente la probabilidad de abstención).
} 
obstante, el efecto no es significativo para los años 1982-89. La figura 5 simula el efecto de la educación. Mientras un votante sin estudios se abstiene con una probabilidad del 15 por ciento, un elector con estudios postsecundarios decide no votar con una probabilidad del 10 por ciento. Esta diferencia es ligeramente superior para la muestra del segundo período.

Las variables ocupacionales tienen un efecto reducido sobre la participación electoral. Manteniendo las restantes variables en sus medias, la probabilidad de abstenerse se reduce en un 2 por ciento cuando el votante trabaja. Este último resultado se refiere a la muestra completa. Durante el período 1982-89, tener un trabajo incrementa la probabilidad de votar en un 5 por ciento. En el segundo período, no obstante, esta variable no es significativa. Por su parte, los votantes jubilados tienden a votar menos -- pero el efecto es muy reducido y queda enteramente compensado por el incremento en la participación electoral asociado con la edad.

\section{[Figura 6 aquí]}

El tamaño de la población en la que vive el elector muestra una correlación positiva con la probabilidad de abstenerse. El coeficiente, que es significativo, es extremadamente estable en todas las tablas. La figura 6 simula el efecto del tamaño del hábitat. En núcleos rurales la probabilidad de abstenerse se sitúa en torno al 10 por ciento o unos 5 puntos por debajo de las ciudades de más de 1 millón de habitantes. Las diferencias en función del lugar de residencia se han acentuado ligeramente con el curso de los años. La mayor participación en las áreas rurales puede deberse a varios factores. Por una parte, el tamaño mismo de los núcleos pequeños conduce a un mayor control social y, por tanto, a una mayor presión sobre los ciudadanos a votar. Por otra parte, es posible imaginar que en las áreas rurales, con economías menos diversificadas y mayor dependencia de transferencias y servicios públicos, las elecciones tienen mayor relevancia que en las ciudades. En la tabla 2 se ha introducido el nivel de transferencias netas que recibe cada provincia, para controlar por este último efecto. Los coeficientes de la variable 'tamaño del hábitat' del votante apenas se modifican. Este resultado sugiere que es la presión social existente en núcleos pequeños hacia aquellos que se desvían de una norma generalizda lo que probablemente conduce a una mayor participación en zonas rurales.

Las variables estrictamente ocupacionales que se incluyen en la tabla 2 no son significativas para 
1982-89. Lo son, por el contrario, para 1993-96. Con dos excepciones (profesionales y trabajadores del sector servicios), todas ellas tienen un efecto reductor (similar) sobre la abstención. La probabilidad de abstenerse decae en especial entre profesionales y empresarios con asalariados (en unos 4 puntos porcentuales) y entre capataces.

Por último, la tabla 2 incluye varios factores socioeconómicos a nivel provincial. Un incremento en el paro provincial contribuye a aumentar la abstención. Un incremento de la tasa de paro en un 1 por ciento se traslada en un un aumento de la abstención de un 0,3 por ciento. Asimismo las provincias agrícolas e industriales registran niveles algo más elevados de abstención. Por cada punto porcentual de sector agrícola o sector industrial, la participación desciende en un 0,4 por ciento.

Las encuestas postelectorales manejadas no incluyen información sobre los ingresos de los votantes. Para aproximar su renta, hemos introducido la renta per cápita provincial así como el nivel de transferencias públicas netas. Ambos factores afectan positivamente la abstención. A medida que la renta per cápita aumenta, un mayor número de personas se abstiene en cada provincia. La probabilidad de que un votante se abstenga aumenta en un 4 por ciento por cada 100,000 pesetas de renta per cápita (en pesetas de 1982). ${ }^{12}$ Este resultado no se aviene con la teoría de recursos, examinada previamente, que postula una reducción en la participación a medida que aumenta la renta personal. Puesto que la regresión controla por el tipo de población, no parece plausible concluir que la variable renta per cápita está simplemente aproximando otros factores tales como el grado de urbanización o la distribución geográfica de la población. Cuando se controla por la proporción de la población urbana en cada provincia, el efecto de la variable renta per cápita continúa siendo significativo y estable.

Dadas las restricciones en términos de datos con las que nos encontramos, es difícil determinar qué se oculta tras el impacto de la renta per cápita. Una posible explicación reside en un cambio en las pautas de movilización política en el transcurso de la década. En las últimas elecciones, las provincias menos desarrolladas han cerrado la brecha que existía entre ellas y las circunscripciones electorales más desarrolladas en las primeras elecciones democráticas. Este incremento en la movilización se puede

\footnotetext{
${ }^{12}$ La renta per cápita provincial media es de 544,245 pesetas (de 1982) en la muestra.
} 
atribuir a la penetración del Partido Socialista en áreas en las que tenía escasa implantación y que, al recibir un número más elevado de servicios y transferencias, pasan a participar más activamente en elecciones que previamente no se consideraban relevantes. Evidencia de este proceso de movilización en favor del PSOE entre electorados tradicionalmente no socialistas en zonas poco urbanizadas se puede hallar en Boix (1996). Esta hipótesis recibiría apoyo claro si el nivel de transferencias públicas condujese a reducir el nivel de abstención. El resultado obtenido es, sin embargo, el opuesto. En aquellas provincias que son receptoras netas, la abstención es mayor. En nuestra opinión, la fuerte correlación negativa entre renta per cápita y volumen de transferencias recibidas hace difícil determinar un efecto independiente de estas últimas sobre la abstención. Es necesario posponer toda conclusión firme hasta que se puedan hacer análisis más precisos de la relación entre renta per cápita y abstención.

\section{RESULTADOS (II). MOVILIZACIÓN ESTRATÉGICA E INSTITUCIONES POLÍTICAS.}

En las tablas 3 y 4 procedemos a examinar el impacto de la movilización estratégica por parte de las élites políticas y el efecto de las instituciones políticas sobre la abstención en las elecciones generales españolas.

Tomando como punto de partida el modelo de la tabla 1, hemos extendido el estudio a fin de considerar el impacto de las variables político-institucionales enumeradas en los apartados 2 y 3 de la sección 4. La tabla 3 solamente incluye aquellas variables políticas e institucionales que son significativas desde un punto de vista estadístico. En la tabla 4 añadimos dos variables políticas de carácter individual: el grado de interés del encuestado por la campaña electoral y la distancia entre la autoubicación ideológica del encuestado y la media ideológica del electorado español. La primera variable solamente se incluyó en las encuestas postelectorales de 1989 y 1993 y por esta razón presentamos las regresiones que la incluyen en una tabla separada.

\subsection{Satisfacción global y abstención.}

Considérese, en primer lugar, el efecto que el juicio de la situación política y económica tiene sobre los electores. El tipo de juicio (positivo o negativo) que los electores emiten, a título individual, 
sobre la situación económica y política no tiene efectos sobre su decisión de votar o abstenerse. ${ }^{13}$ Una posible explicación quizá resida en la relación que se da entre las preferencias ideológicas de los votantes españoles y el tipo de evaluaciones que estos realizan del gobierno y del partido de oposición. (Maravall y Przeworski 1998).

[Tabla 3 y figura 7 aquí]

Por el contrario, el nivel de satisfacción del electorado en su conjunto tiene un efecto sustancial sobre la abstención. La figura 7 simula el impacto que el porcentaje de personas satisfechas con la situación política tiene sobre la participación. El incremento del número de ciudadanos que juzga que se han deteriorado las condiciones políticas del país conduce a una reducción importante de de la abstención. Un incremento de un 5 por ciento en la proporción de insatisfechos con la situación política supone una caída de la abstención de un punto porcentual. Una crisis económica o política aguda no se traduce, por tanto, en una mayor apatía sino en un interés mayor en participar.

Este resultado, robusto a las diferentes especificaciones del modelo, conduce a concluir que una parte importante de cambios en la estructura de voto, en la representación del Parlamento y en la composición ideológica del gobierno se debe en mayor medida a la movilización de ciertos votantes en momentos de crisis que a cambios en el sentido del voto de los electores que participan sistemáticamente. Es decir, una situación crítica (como las crisis económicas de principios de cada década) empuja ciertos votantes reticentes a volver a las urnas para castigar al gobierno existente y producir un vuelco electoral. ${ }^{14}$

\subsection{Movilización política y participación electoral.}

Los resultados de la tabla 3 muestran que la vida asociativa de cada provincia afecta

\footnotetext{
${ }^{13}$ Los resultados no se incluyen en este informe.

${ }^{14}$ Un argumento más general, que requiere una mayor investigación, parece derivarse de los datos observados en España. La teoría del voto económico sugiere que, en épocas de crisis económica, el elector castiga el gobierno de turno votando la oposición. Esta hipótesis, no obstante, deja de lado la importancia de la ideología y de la adscripción partidista en cada país. Es posible que, en aquellos sistemas políticos con electores fuertemente 'anclados' en ciertos bloques ideolólogicos, como España, el castigo no tenga lugar mediante un cambio en el sentido del voto si no mediante el paso de una situación de participación a una de abstención.
} 
positivamente el nivel de participación. En aquellas circunscripciones electorales con un nivel mínimo de asociacionismo (alrededor de 2 asociaciones por cada 1.000 habitantes), la abstención se sitúa en torno al 17 por ciento -- véase la simulación en la figura 8. Por el contrario, en aquellas áreas con una cierta densidad asociativa (7,8 asociaciones por cada 1.000 habitantes -- el número máximo en España), la abstención retrocede hasta el 8 por ciento. ${ }^{15}$ La existencia de una vida asociativa más densa favorece la participación mediante varios mecanismos: abarata el coste de obtener información sobre candidatos y partidos, aumenta la probabilidad de que los miembros de asociaciones sean objeto de la actividad de movilización de los partidos políticos (Rosenstone y Hansen 1993), incrementa el sentido de eficacia de los miembros de asociaciones, y refuerza la naturaleza cívica y el compromiso político de aquellos (Putnam 1993).

[Figuras 8 y 9 aquí]

La movilización estratégica por parte de los candidatos depende, en buena medida, de los recursos de las organizaciones políticas. Aunque los datos son escasos, un posible indicador se da en el grado de militancia política a nivel de circunscripción provincial. A mayor militancia, cabe esperar mayor capacidad de movilización y menor abstención. La militancia socialista tiene un impacto negativo y estadísticamente significativo sobre la abstención. Tal como muestra la simulación en la figura 9, en provincias con una militancia escasa (3 militantes por cada 1.000 habitantes), todo votante tiene una probabilidad de abstenerse del 16 por ciento. En provincias con un alto grado de militancia (24 militantes por cada 1.000 habitantes), la probabilidad de abstenerse cae al 10 por ciento. Es interesante subrayar el hecho (por otra parte, lógico) de que la capacidad de movilización del PSOE haya aumentado en el período 1993-96, esto es, en un período de mayor competitividad electoral.

[Figura 10 aquí]

El grado de competitividad electoral tiene relevancia tan sólo en el último período bajo examen.

\footnotetext{
${ }^{15}$ Desafortunadamente ninguna de las encuestas incluye preguntas sobre la participación de los encuestados en asociaciones. Por esta razón no es posible examinar separadamente el efecto que sobre la abstención tiene la participación personal en una asociación y el efecto contextual de vivir en un área con una mayor vida asociativa.
} 
El resultado no es extraño puesto que solamente a partir de 1993 puede hablarse en propiedad de equilibrio de fuerzas electorales en un número importante de circunscripciones. El coeficiente se aviene a nuestras predicciones teóricas. A medida que la situación se hace más competitiva, la relevancia del voto marginal aumenta y la abstención se reduce. En todo caso, el efecto no es extremadamente importante. La figura 10 muestra que, en el período 1993-96, una reducción en la ventaja del primer partido sobre el segundo partido en las elecciones anteriores incrementa la probabilidad de votar en un 0,1 por ciento en las siguientes elecciones.

\subsection{Instituciones electorales y abstención.}

El papel que las instituciones electorales juegan en la decisión de participar en unas elecciones ha sido puesto de manifiesto repetidas veces en la literatura especializada en el contexto de estudios comparativos entre naciones (Franklin 1996) y, más recientemente, en los Estados Unidos (Rosenstone y Hansen 1993). La existencia de voto obligatorio, la posibilidad de votar por correo y el grado de proporcionalidad aumentan el nivel de participación (Franklin 1996). A su vez, la facilidad de registrarse como elector (que varía según el estado de los Estados Unidos) afecta el grado de participación notablemente.

[Figura 11 aquí]

En España la ley electoral impone un sistema uniforme en todo el país en el procedimiento para censarse y votar. No obstante, las circunscripciones electorales varían en tamaño desde 1 escaño (Ceuta, Melilla) hasta 33 escaños (Madrid) y por tanto en la proporcionalidad de la representación. En los distritos uninominales, un partido necesita en torno al 50 por ciento de los votos para obtener el escaño en disputa. En Madrid, y dada la existencia de una barrera legal mínima, basta conseguir un 3 por ciento de los votos para asegurarse la entrada en el Parlamento. A medida que el tamaño del distrito se reduce y el umbral necesario para obtener un escaño se eleva, es plausible que los votantes partidarios de grupos minoritarios decidan abstenerse en vez de votar (especialmente si sus preferencias son tan intensas que prefieren no votar un partido alternativo al que constituye su primera preferencia).

Efectivamente, el tamaño del distrito tiene un efecto extremadamente sustancial (y similar en 
todos los años) sobre la decisión de votar. La figura 11 representa el efecto de la llamada barrera electoral efectiva. Cuando esta es el 3 por ciento (el mínimo que impone la ley electoral española), la abstención es del 11 por ciento. En el distrito medio español (de 7 escaños y una barrera efectiva del 10 por ciento), la abstención alcanza el 13,5 por ciento. En distritos de 5 escaños se eleva al 16,5 por ciento. En distritos uninominales (en los que la barrera efectiva es del 35 por ciento) alcanza el 27 por ciento.

La literatura ha subrayado que el tamaño del distrito reduce la proporcionalidad de la representación mediante dos mecanismos: uno mecánico, debido a que el número de escaños es siempre menor que el número de votos de cada partido; y un efecto estratégico, que consiste en que, por razón de las instituciones electorales existentes, votantes (y élites políticas) tienden a coordinarse en torno a los candidatos con más posibilidades de obtener el escaño en disputa. Los resultados obtenidos sugieren un tercer mecanismo que no se ha discutido de manera explícita en la literatura sobre las consecuencias de diferentes sistemas electorales: la reducción del grado de proporcionalidad conduce a la alienación y abstención (en vez del puro voto estratégico) de aquellos votantes de partidos con pocas probabilidades de elección. ${ }^{16}$

\subsection{Interés por la campaña electoral y participación electoral.}

En las encuestas postelectorales de 1989 y 1993, los encuestados fueron objeto de una serie de preguntas sobre su interés en la campaña electoral y sobre las consecuencias de esta sobre sus opiniones. Confirmando los resultados de estudios anteriores, el interés o motivación por la vida política tiene un impacto importante sobre la decisión de votar.

[Tabla 4 aquí]

La simulación del efecto del interés por la campaña electoral se ofrece en la figura $12 .{ }^{17}$ Para la muestra completa (elecciones de 1989 y 1993), la probabilidad de abstenerse es del 3 por ciento entre los

\footnotetext{
${ }^{16}$ Nuestros resultados demuestran de manera empírica la existencia de una conexión teórica importante entre los modelos electorales espaciales y la literatura sobre sistemas electorales - a saber, que a medida que la representatividad de las instituciones decae, la abstención (por alienación) aumenta.

${ }^{17}$ Las simulaciones representadas en las figuras 12 y 13 emplean las regresiones de la tabla 4.
} 
que declaran haber seguido la campaña con mucho interés pero alcanza el 29 por ciento entre los que no muestran ningún interés. El diferencial entre ambos extremos se agudiza para la campaña de 1989: la probabilidad de abstenerse aumenta hasta un 33 por ciento entre los electores no interesados en la campaña. Por el contrario, en la campaña de 1993, la probabilidad de abstenerse desciende al 24 por ciento (el resultado global en la encuesta) entre estos últimos. Otros factores, emergentes en 1993 y 1996, tales como la insatisfacción con la situación política y un aumento en la competitividad entre partidos, debió de empujar a los más indiferentes a votar en mayores proporciones.

[Figura 12 aquí]

La introducción de la variable 'interés en la campaña electoral' modifica parcialmente algunos de los coeficientes de las variables empleadas en las anteriores regresiones (tablas 1 a 3). La edad pierde influencia: la diferencia en la probabilidad de abstenerse entre los más jóvenes y los más mayores pasa de un 17 a un 4,5 por ciento. El nivel educativo invierte su efecto sobre la decisión de abstenerse: a mayor educación, y una vez se controla por interés, aumenta la probabilidad de no votar. El efecto de la educación continúa siendo, en todo caso, extremadamente reducido. La existencia de asociaciones reduce la probabilidad de abstenerse en 1989. Sin embargo, el coeficiente deja de ser significativo para la muestra total y para el año 1993.

El tamaño del hábitat y las restantes variables político-institucionales se mantienen, por el contrario, robustas a la introducción de la variable interés. De hecho, la importancia de la competitividad electoral se dobla para 1993. La existencia de un umbral efectivo elevado continúa ejerciendo un efecto disuasorio sobre los votantes con excepción del año 1993.

En los modelos electorales espaciales, en los que los votantes votan al candidato más cercano a sus posiciones para maximizar su utilidad, el fenómeno de la abstención se atribuye a dos factores contrapuestos. De una parte, el votante puede abstenerse por indiferencia, es decir, la percepción de que no hay diferencias importantes (en lo que se refiere a su bienestar) entre las alternativas presentadas por los candidatos en liza. En términos más formales, dado que la diferencia en la utilidad que cada una de las dos alternativas le deparan es cero y que votar tiene (por mínimo que sea) algún coste, el votante decide abstenerse. De otra parte, el votante puede abstenerse por alienación, es decir, la convicción del votante 
de que las alternativas presentadas se hallan alejadas de sus intereses, es decir, que le reportan una utilidad mínima o cero. En este supuesto, e incluso si uno de los candidatos se halla más cerca del votante que el otro, el elector terminará absteniéndose.

[Figura 13 aquí]

En la investigación que hemos realizado, hemos hallado indicios directos de abstención por indiferencia. Los resultados de la tabla 4 muestran que a medida que el elector se sitúa en posiciones ideológicas más alejadas de la media española la probabilidad de abstenerse decae. Es posible observar mediante la simulación en la figura 13 que el efecto es, no obstante, pequeño. La probabilidad de abstenerse disminuye en un 3 por ciento al aproximarse a los extremos. Es necesario advertir que este resultado no excluye la existencia de abstención por alienación. El hecho de que barreras electorales mayores desincentivan la participación es, por el contrario, un buen indicador de la existencia de una abstención por alienación sustancial en ciertos sectores del electorado.

De la investigación realizada cabe concluir, finalmente, que la probabilidad de abstenerse no varía según la afiliación ideológica de los votantes y sus simpatías políticas. De acuerdo a resultados no presentados en las tablas por no ser estadísticamente significativos, no existen diferencias en la probabilidad de votar entre electores de izquierda y de derecha o entre simpatizantes de partidos y líderes específicos.

\section{CONCLUSIONES.}

A tenor del análisis llevado a cabo y presentado en este informe, las fluctuaciones intertemporales y las diferencias entre individuos en el nivel de participación en las elecciones generales en España se debe a la suma de un conjunto de factores heterogéneos y desiguales en sus efectos.

Con excepción de la edad del votante, las características individuales tienen un impacto reducido sobre la decisión de votar. Las diferencias en educación modifican la probabilidad de votar en un 5 por ciento aproximadamente. La participación en el mercado de trabajo reduce la probabilidad de abstenerse en un mero 2 por ciento. De acuerdo con las simulaciones realizadas en secciones anteriores, la probabilidad de abstenerse es cuatro veces mayor entre jóvenes que entre ancianos. En todo caso, la 
importancia de las características individuales se reduce todavía más cuando, en las encuestas de 1989 y 1993, controlamos por el interés que el encuestado declara por la campaña electoral.

La escasa influencia de las variables individuales apunta el resultado fundamental de este estudio. La abstención en el electorado español tiene una fuerte raigambre social y política. La motivación del elector, medida por su interés en la campaña, constituye el factor más relevante en la existencia de abstención. Otros factores políticos e institucionales tiene, sin embargo, un peso notable. La evolución de la situación política y económica del país se traduce en cambios importantes en la decisión de votar. En momentos de satisfacción generalizada, la abstención declarada se sitúa en torno al 14 por ciento. Sin embargo, en momentos percibidos por el electorado como críticos, la abstención decae al 5 por ciento o una tercera parte del primer valor. ${ }^{18}$ La decisión de votar se articula en contextos de movilización social y política diferentes y estas diferencias son relevantes según nuestro estudio. En provincias con una vida asociativa intensa, la probabilidad de abstenerse es tres veces menor (un 6 por ciento) que en provincias sin vida asociativa (un 16 por ciento). La presencia de organizaciones políticas desarrolladas contribuye asimismo a reducir la abstención.

El electorado español es un electorado estratégico. El aumento en la competitividad de las elecciones conduce a una mayor participación (aun cuando el efecto es pequeño). Asimismo, entre electores centristas, los incentivos para votar son, tal como predice la literatura espacial, menores que entre los electores extremistas. El efecto más importante proviene de la existencia de distorsiones en el sistema electoral. En circunscripciones pequeñas, que constituyen una parte no desdeñable del territorio, la tasa de abstención es casi dos veces la tasa en circunscripciones como Madrid y Barcelona -- siempre controlando por la presencia de otros factores individuales y sociopolíticos. Este resultado, que coincide con las conclusiones de estudios que comparan sistemas electorales en países distintos, es notable puesto que es el primero que se obtiene en un estudio basado en un solo país.

Aunque la abstención española es mayor que la abstención media en otros países europeos, las

\footnotetext{
${ }^{18}$ Recuérdese que estas cifras se derivan de simulaciones en las que las restantes variables se han fijado en sus medias.
} 
causas de la abstención en España acercan nuestro país mucho más a Europa que a los Estados Unidos. En último país, el grado de movilización estratégica por los partidos es bajo y las instituciones electorales imponen unos requisitos que desincentivan la participación electoral. Como consecuencia, las diferencias interpersonales en recursos individuales (educación e ingresos) determinan una parte sustancial de la variación en la abstención. En España, por el contrario, el grado de movilización política es importante y la traducción política de las diferencias en recursos en nuestra sociedad (en flujos de renta o niveles educativos) es mínima en el campo de la participación.

La abstención en las elecciones generales españolas es, en definitiva, un fenómeno político. Si desea lograr resultados fructíferos, toda investigación futura sobre el fenómeno de la participación electoral en España deberá partir de esta base. Es decir, al tratar de modelar y capturar las razones que explican la extraordinaria variabilidad en la participación electoral que se da en nuestras elecciones generales, autonómicas, locales o europeas, deberá hacer hincapié en los siguientes elementos: la relevancia (objetiva y subjetiva) de las instituciones que se eligen; la distribución del electorado en el espacio político (izquierda-derecha o, en ciertas comunidades, de identidad nacional) y los cálculos que los electores hacen sobre las diferencias ideológicas entre fuerzas políticas; las estrategias de las élites políticas; y el papel de las reglas electorales y de representación. 


\section{BIBLIOGRAFÍA}

Aldrich, John H. 1997. “When is it rational to vote?” en Dennis C. Mueller, ed. Perspectives on Public Choice: A Handbook. New York: Cambridge, capítulo 17.

Crewe, Ivor. 1981. “Electoral Participation”, en, David Butler, Howard Penniman y Austin Ranney, eds. Democracy at the Polls. Washington, D.C.: American Enterprise Institute.

Boix, Carles. 1996. Partidos políticos, crecimiento e igualdad. Estrategias económicas conservadoras y socialdemócratas en la economía mundial. Madrid: Alianza Editorial, Colección Alianza Universidad.

Font, Joan. 1995. "La abstención en España: Certezas e interrogantes", Revista Española de Investigaciones Sociológicas, 71-72, pp. 11-37.

Franklin, Mark N. 1996. "Electoral Participation”, en Lawrence LeDuc, Richard G. Niemi y Pippa Norris, eds. Comparing Democracies. Elections and Voting in Global Perspective. Thousand Oaks: Sage.

Hicks, Alexander M. y Swank, Dwane H. 1992. "Politics, Institutions and Welfare Spending in Industrialized Democracies, 1960-82,” American Political Science Review 86: 658-74.

Jackman, Robert. 1987. "Political Institutions and Voter Turnout in the Industrial Democracies", American Political Science Review 81: 405-23.

Justel, Manuel. 1990. "Panorama de la abstención electoral en España", Revista de Estudios Políticos, 68, pp. 343-397.

Justel, Manuel. 1995. La abstención electoral en España, 1977-1993. Madrid: CIS.

King, Gary. 1990. Unifying Political Methodology. The Likelihood Theory of Statistical Inference Cambridge: Cambridge University Press.

King, Gary. 1997. A Solution to the Ecological Inference Problem. Princeton: Princeton University Press. Maravall, José María y Adam Przeworski. 1998. "Political Reactions to the Economy: The Spanish Experience", Madrid, manuscrito sin publicar.

Meltzer, A.H. and S. F. Richards. 1981. "A Rational Theory of the Size of Government,” Journal of Political Economy 89: 914-927. 
Montero, José Ramón. 1984. "Niveles, fluctuaciones y tendencias del abstencionismo electoral en España y en Europa", Revista Española de Investigaciones Sociológicas, 28, pp. 223-42.

Montero, José Ramón. 1986. "La abstención electoral en las elecciones legislativas de 1982: términos de referencia, pautas de distribución y factores políticos", Revista de Estudios Políticos, 22, pp. 10347.

Montero, José Ramón y Mariano Torcal. 1997. "Facets of social capital in new democracies: the formation and consequences of social capital in Spain". Manuscrito sin publicar.

Nagel, J. H.. 1987. Participation. Englewood Cliffs: Prentice-Hall.

Pampel, F. y J. Williamson. 1988. "Welfare Spending in Advanced Industrial Democracies 1950-1980" American Journal of Sociology 93: 1424-56.

Powell, G. Bingham Jr. 1980. "Voting Turnout in Thirty Democracies: Partisan, Legal and SocioEconomic Influences", en Richard Rose, ed. Electoral Participation: A Comparative Perspective. London: Sage.

Riba, Clara. 1995. "Vot dual i abstenció diferencial". Tesis doctoral, Universitat Autònoma de Barcelona. Reif, Karlheinz. 1985. “Ten Second-Order Elections”, en Karlheinz Reif, ed. Ten European Elections. Aldershot: Gower.

Reif, Karlheinz y Hermann Schmitt. 1980. "Nine Second-Order National Elections: A Conceptual Framework for the Analysis of European Election Results," European Journal of Political Research 8: 3-44.

Rosenstone, Steven J. y John Mark Hansen. 1993. Mobilization, Participation, and Democracy in America. New York: Macmillan.

Taagapera, Rein and Matthew S. Shugart. 1989. Seats and Votes: The Effects and Determinants of Electoral Systems. New Haven: Yale University Press.

Van der Eijk, Cees et al. 1996. Choosing Europe? The European Electorate and National Politics in the Face of the Union. Ann Arbor: University of Michigan Press.

Verba, Sidney y Norman H. Nie. 1972. Participation in America: Political Democracy and Social Equality. New York: Harper and Row. 


\section{TABLAS}

Tabla 1. El efecto de las variables sociológicas individuales

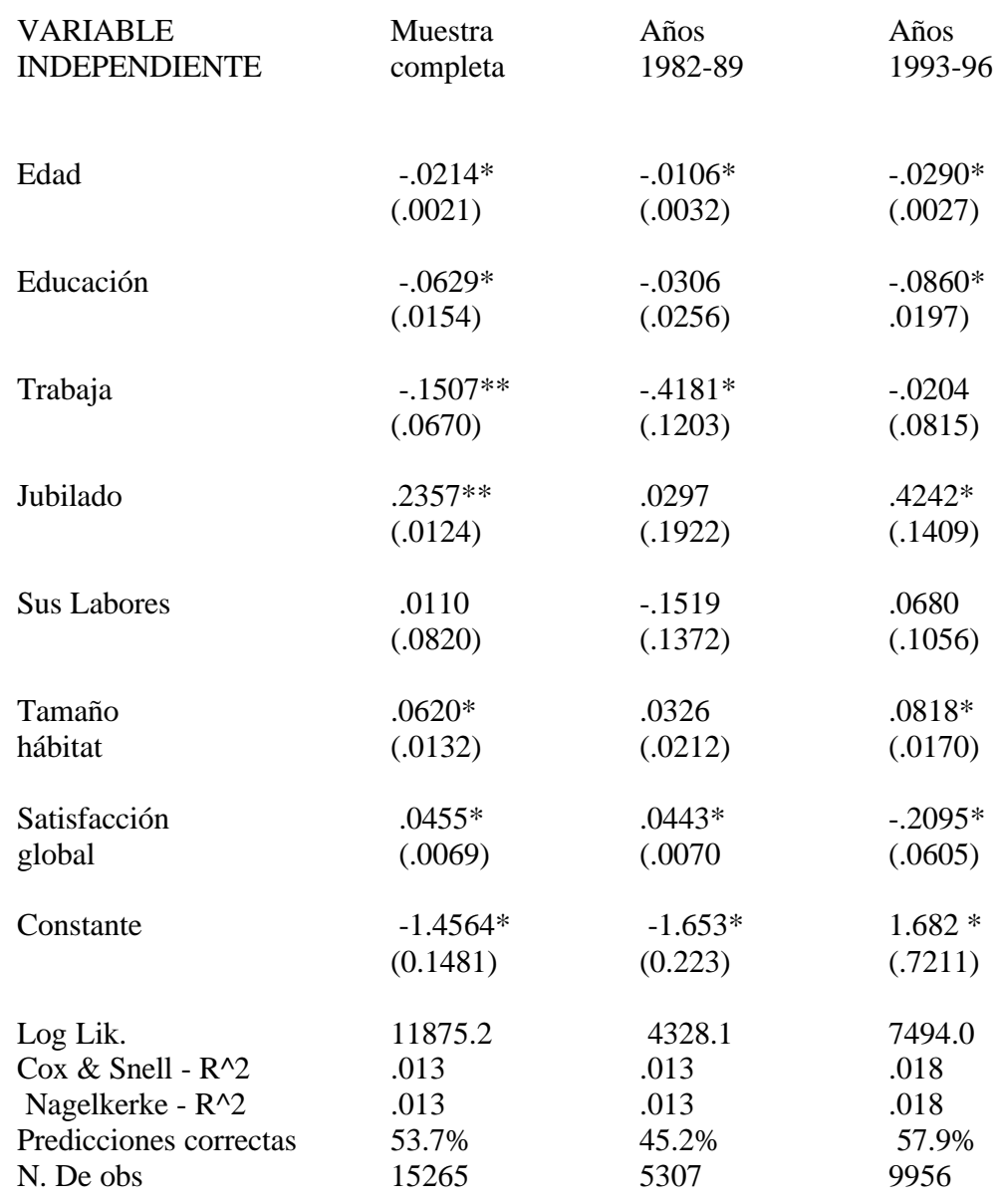

Estmación logística.

Errores estándar entre paréntesis.

* Estadísticamente significativo al nivel 0.01.

** Estadísticamente significativo al nivel 0.05

*** Estadísticamente significativo al nivel 0.10. 
Tabla 2. El efecto de variables sociológicas individuales, variables ocupacionales y variables sociológicas provinciales

\begin{tabular}{|c|c|c|}
\hline VARIABLE & Años & Años \\
\hline INDEPENDIENTE & $1982-89$ & $1993-96$ \\
\hline Edad & $\begin{array}{l}-.0120^{*} \\
(.0034)\end{array}$ & $\begin{array}{l}-.0280^{*} \\
(.0028)\end{array}$ \\
\hline Educación & $\begin{array}{l}-.0504 * * * \\
(.0311)\end{array}$ & $\begin{array}{l}-.0742 * \\
(.0221)\end{array}$ \\
\hline Trabaja & $\begin{array}{l}-.5243 * \\
(.1259)\end{array}$ & $\begin{array}{l}-.0622 \\
(.0835)\end{array}$ \\
\hline Jubilado & $\begin{array}{l}-.0603 \\
(.1976)\end{array}$ & $\begin{array}{l}.4161^{*} \\
(.1426)\end{array}$ \\
\hline Sus Labores & $\begin{array}{l}-.2170 \\
(.1415)\end{array}$ & $\begin{array}{l}.0835 \\
(.1073)\end{array}$ \\
\hline $\begin{array}{l}\text { Tamaño } \\
\text { hábitat }\end{array}$ & $\begin{array}{l}.0618 * * \\
(.0266)\end{array}$ & $\begin{array}{l}.0954^{*} \\
(.0215)\end{array}$ \\
\hline $\begin{array}{l}\text { Satisfacción } \\
\text { global }\end{array}$ & $\begin{array}{l}.0449 * \\
(.0089)\end{array}$ & $\begin{array}{l}.0456 \\
(.0954)\end{array}$ \\
\hline $\begin{array}{l}\text { Profesionales } \\
\text { con asalariados }\end{array}$ & & $\begin{array}{l}-.9395 \\
(.6207)\end{array}$ \\
\hline $\begin{array}{l}\text { Empresarios } \\
\text { con asalariados }\end{array}$ & $\begin{array}{l}.2030 \\
(.4058)\end{array}$ & $\begin{array}{l}-.8242 * \\
(.2179)\end{array}$ \\
\hline $\begin{array}{l}\text { Profesionales } \\
\text { sin asalariados }\end{array}$ & $\begin{array}{l}.0152 \\
(.2674)\end{array}$ & $\begin{array}{l}.1812 \\
(.2587)\end{array}$ \\
\hline $\begin{array}{l}\text { Empresarios autónomos } \\
\text { agrícolas }\end{array}$ & $\begin{array}{l}.4890 \\
(.3061)\end{array}$ & $\begin{array}{l}-.3329 * * * \\
(.1978)\end{array}$ \\
\hline $\begin{array}{l}\text { Empresarios auónomos } \\
\text { en industria y servicios }\end{array}$ & $\begin{array}{l}.1733 \\
(.2684)\end{array}$ & \\
\hline $\begin{array}{l}\text { Empresarios autónomos } \\
\text { industriales }\end{array}$ & & $\begin{array}{l}-.2221 \\
(.1762)\end{array}$ \\
\hline $\begin{array}{l}\text { Empresarios autónomos } \\
\text { de servicios }\end{array}$ & & $\begin{array}{l}-.5690 * \\
(.1765)\end{array}$ \\
\hline Directivos & $\begin{array}{l}.1583 \\
(.4304)\end{array}$ & $\begin{array}{l}-.5229 * * \\
(.2306)\end{array}$ \\
\hline Cuadros medios & $\begin{array}{l}.6278 * * \\
(.2759)\end{array}$ & $\begin{array}{l}-.5251^{*} \\
(.1665)\end{array}$ \\
\hline Empleados de oficina & $\begin{array}{l}.1771 \\
(.2667)\end{array}$ & $\begin{array}{l}-.6551 * \\
(.1988)\end{array}$ \\
\hline Vendedores & $\begin{array}{l}.3951 \\
(.3005)\end{array}$ & $\begin{array}{l}-.5186^{*} \\
(.1968)\end{array}$ \\
\hline Capataces & & $-.7911 *$ \\
\hline
\end{tabular}




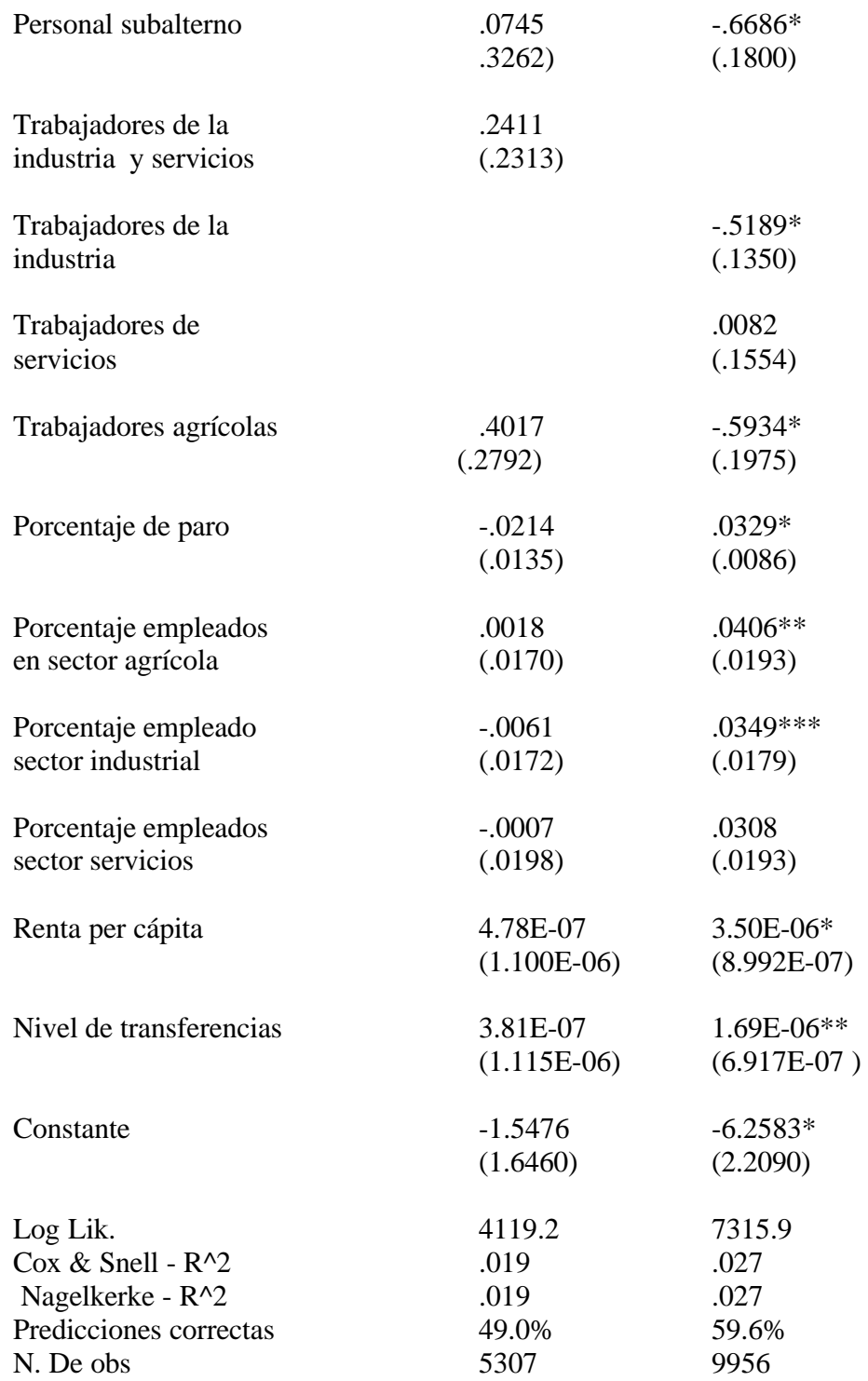

Estmación logística.

Errores estándar entre paréntesis.

* Estadísticamente significativo al nivel 0.01.

** Estadísticamente significativo al nivel 0.05

*** Estadísticamente significativo al nivel 0.10. 
Tabla 3. El efecto de las variables sociológicas individuales y factores político-institucionales

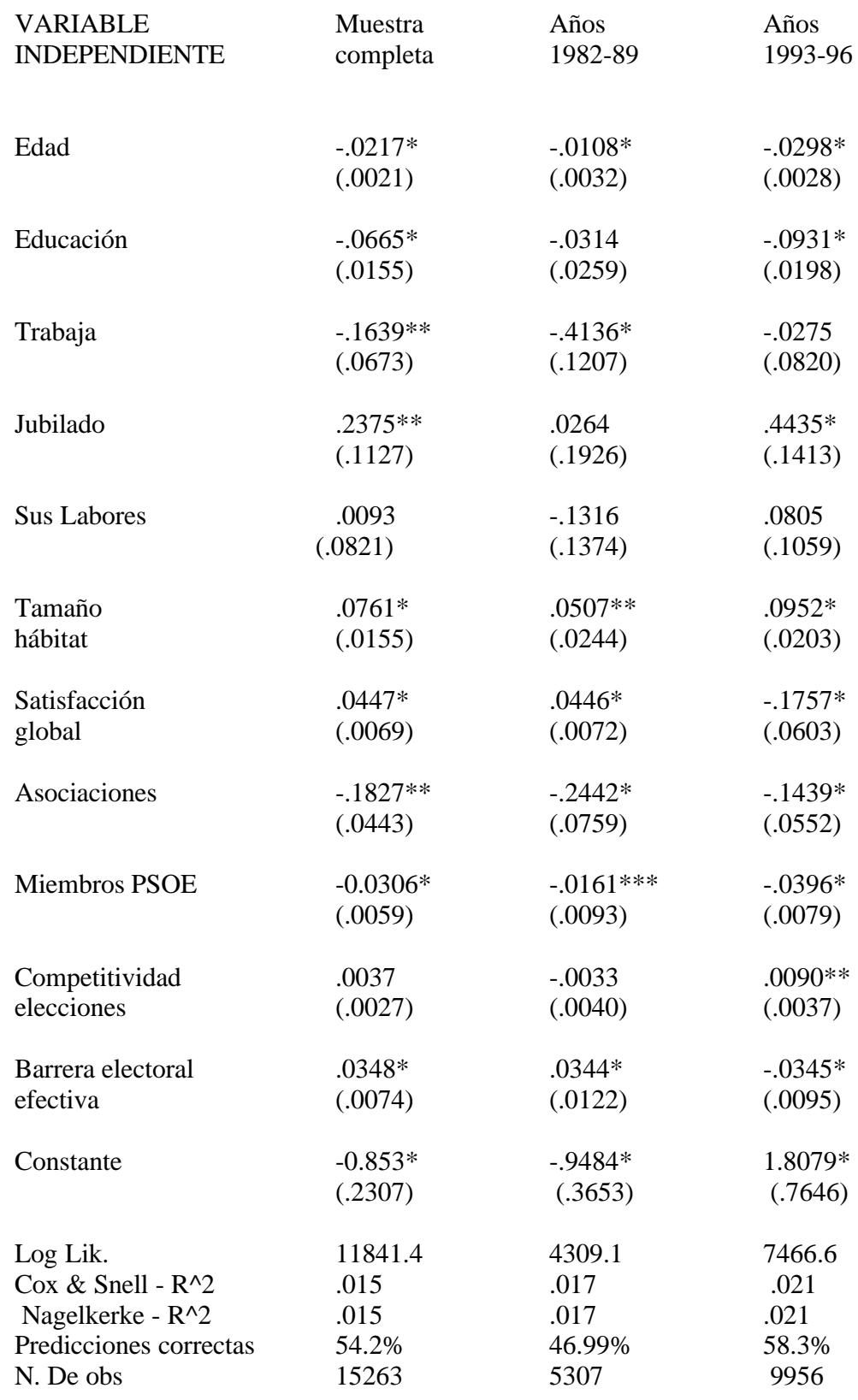

Estmación logística.

Errores estándar entre paréntesis.

* Estadísticamente significativo al nivel 0.01 .

** Estadísticamente significativo al nivel 0.05

*** Estadísticamente significativo al nivel 0.10 . 
Tabla 4. El efecto de las variables sociológicas individuales, factores político-institucionales y variables políticas individuales.

\begin{tabular}{|c|c|c|c|}
\hline $\begin{array}{l}\text { VARIABLE } \\
\text { INDEPENDIENTE }\end{array}$ & $\begin{array}{l}\text { Muestra } \\
\text { completa }\end{array}$ & $\begin{array}{l}\text { Año } \\
1989\end{array}$ & $\begin{array}{l}\text { Año } \\
1993\end{array}$ \\
\hline Edad & $\begin{array}{l}-.0064 * * * \\
(.0039)\end{array}$ & $\begin{array}{l}-.0074 \\
(.0059)\end{array}$ & $\begin{array}{l}-.0071 \\
(.0052)\end{array}$ \\
\hline Educación & $\begin{array}{l}.0751 * \\
(.0282)\end{array}$ & $\begin{array}{l}.0208 \\
(.0414)\end{array}$ & $\begin{array}{l}.1193^{*} \\
(.0393)\end{array}$ \\
\hline Trabaja & $\begin{array}{l}-.1878 \\
(.1185)\end{array}$ & $\begin{array}{l}-.1907 \\
(.1930)\end{array}$ & $\begin{array}{l}-.1585 \\
(.1516)\end{array}$ \\
\hline Jubilado & $\begin{array}{l}.0383 \\
(.2105)\end{array}$ & $\begin{array}{l}.1661 \\
(.3399)\end{array}$ & $\begin{array}{l}.0755 \\
(.2722)\end{array}$ \\
\hline Sus Labores & $\begin{array}{l}-.3129 * * \\
(.1549)\end{array}$ & $\begin{array}{l}-.4321 * * * \\
(.2463)\end{array}$ & $\begin{array}{l}-.1628 \\
(.2011)\end{array}$ \\
\hline $\begin{array}{l}\text { Tamaño } \\
\text { hábitat }\end{array}$ & $\begin{array}{l}.0626 * \\
(.0272)\end{array}$ & $\begin{array}{l}.1320^{*} \\
(.0417)\end{array}$ & $\begin{array}{l}.0107 \\
(.0364)\end{array}$ \\
\hline $\begin{array}{l}\text { Satisfacción } \\
\text { global }\end{array}$ & $\begin{array}{l}.0308 * * \\
(.0147)\end{array}$ & & \\
\hline Asociaciones & $\begin{array}{l}-.0862 \\
(.0752)\end{array}$ & $\begin{array}{l}-.2207 * * * \\
(.1277)\end{array}$ & $\begin{array}{l}.0233 \\
(.0963)\end{array}$ \\
\hline Miembros PSOE & $\begin{array}{l}-.0222 * * \\
(.0118)\end{array}$ & $\begin{array}{l}.0036 \\
(.0182)\end{array}$ & $\begin{array}{l}-.0515^{*} \\
(.0162)\end{array}$ \\
\hline $\begin{array}{l}\text { Competitividad } \\
\text { elecciones }\end{array}$ & $\begin{array}{l}.0037 \\
(.0263)\end{array}$ & $\begin{array}{l}-.0085 \\
(.0083)\end{array}$ & $\begin{array}{l}.0164 * * \\
(.0069)\end{array}$ \\
\hline $\begin{array}{l}\text { Barrera electoral } \\
\text { efectiva }\end{array}$ & $\begin{array}{l}.0263 * * \\
(.0137)\end{array}$ & $\begin{array}{l}.0421 * * * \\
(.0235)\end{array}$ & $\begin{array}{l}.0081 \\
(.0174)\end{array}$ \\
\hline $\begin{array}{l}\text { Interés en la } \\
\text { política }\end{array}$ & $\begin{array}{l}.6525^{*} \\
(.0381)\end{array}$ & $\begin{array}{l}.7776^{*} \\
(.0641)\end{array}$ & $\begin{array}{l}.5935^{*} \\
(.0478)\end{array}$ \\
\hline $\begin{array}{l}\text { Extremismo } \\
\text { ideológico }\end{array}$ & $\begin{array}{l}-.0623 * * * \\
(.0377)\end{array}$ & $\begin{array}{l}-.0711 \\
(.0578)\end{array}$ & $\begin{array}{l}-.0584 \\
(.0505)\end{array}$ \\
\hline Constante & $\begin{array}{l}-4.405^{*} \\
(.4648)\end{array}$ & $\begin{array}{l}-4.0599 * \\
(.6558)\end{array}$ & $\begin{array}{l}-4.0135^{*} \\
(.5396)\end{array}$ \\
\hline $\begin{array}{l}\text { Log Lik. } \\
\text { Cox \& Snell - R^2 } \\
\text { Nagelkerke - R^2 } \\
\text { Predicciones correctas } \\
\text { N. De obs }\end{array}$ & $\begin{array}{l}3776.2 \\
.063 \\
.063 \\
69.5 \% \\
5937\end{array}$ & $\begin{array}{l}1531.5 \\
.086 \\
.086 \\
67.6 \% \\
2256\end{array}$ & $\begin{array}{l}2215.7 \\
.054 \\
.054 \\
73.5 \% \\
3681\end{array}$ \\
\hline \multicolumn{4}{|c|}{$\begin{array}{l}\text { Estmación logística. } \\
\text { Errores estándar entre paréntesis. } \\
* \text { Estadísticamente significativo al nivel } 0.01 . \\
\text { ** Estadísticamente significativo al nivel } 0.05 \\
* * * \text { Estadísticamente significativo al nivel } 0.10 \text {. }\end{array}$} \\
\hline
\end{tabular}


Figura 1

Nivel de abstención según convocatoria electoral

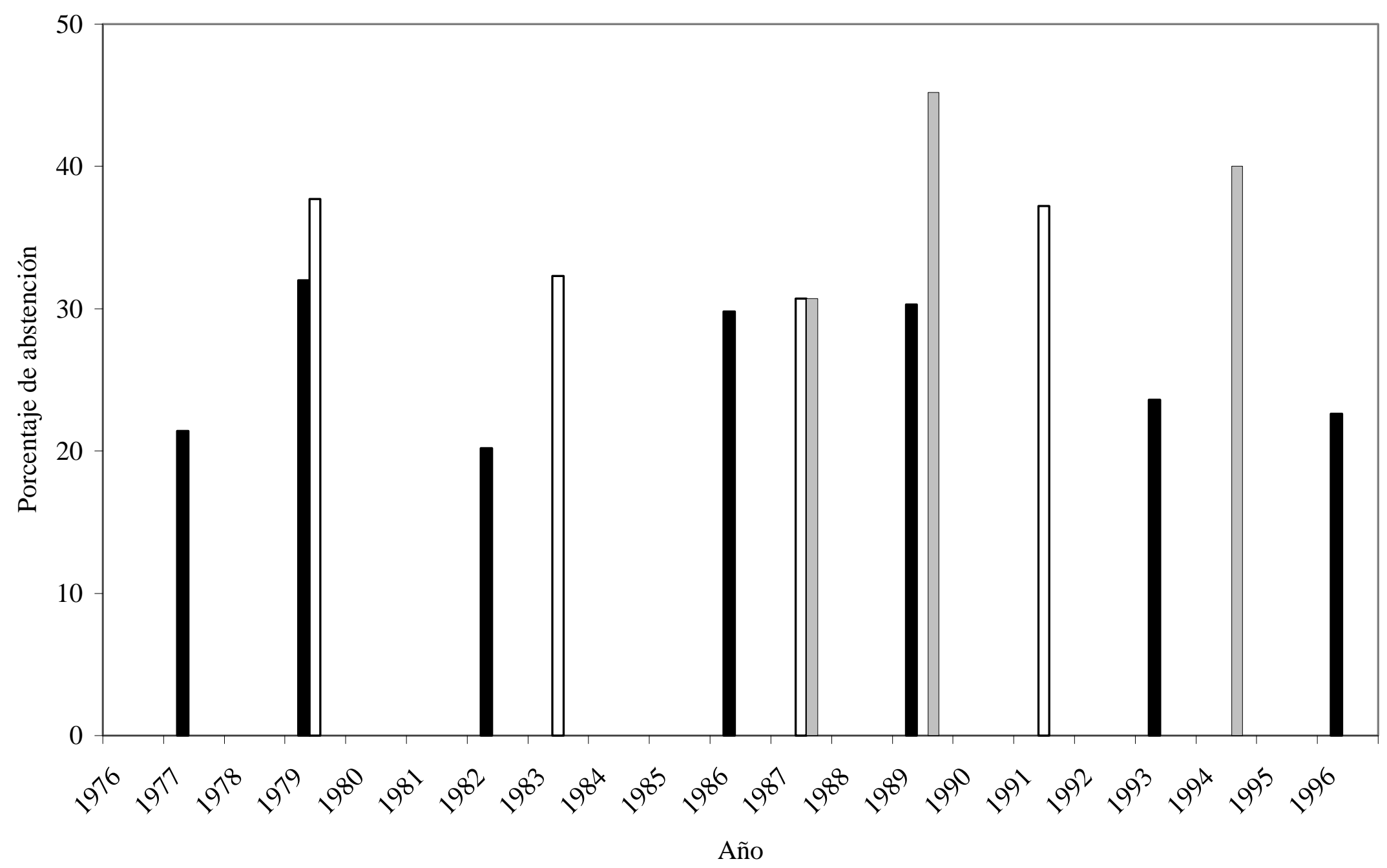

Elecciones generales $\square$ Elecciones municipales $\square$ Elecciones europeas 
Figura 2

Satisfacción del electorado respecto a la situación del país y participación electoral

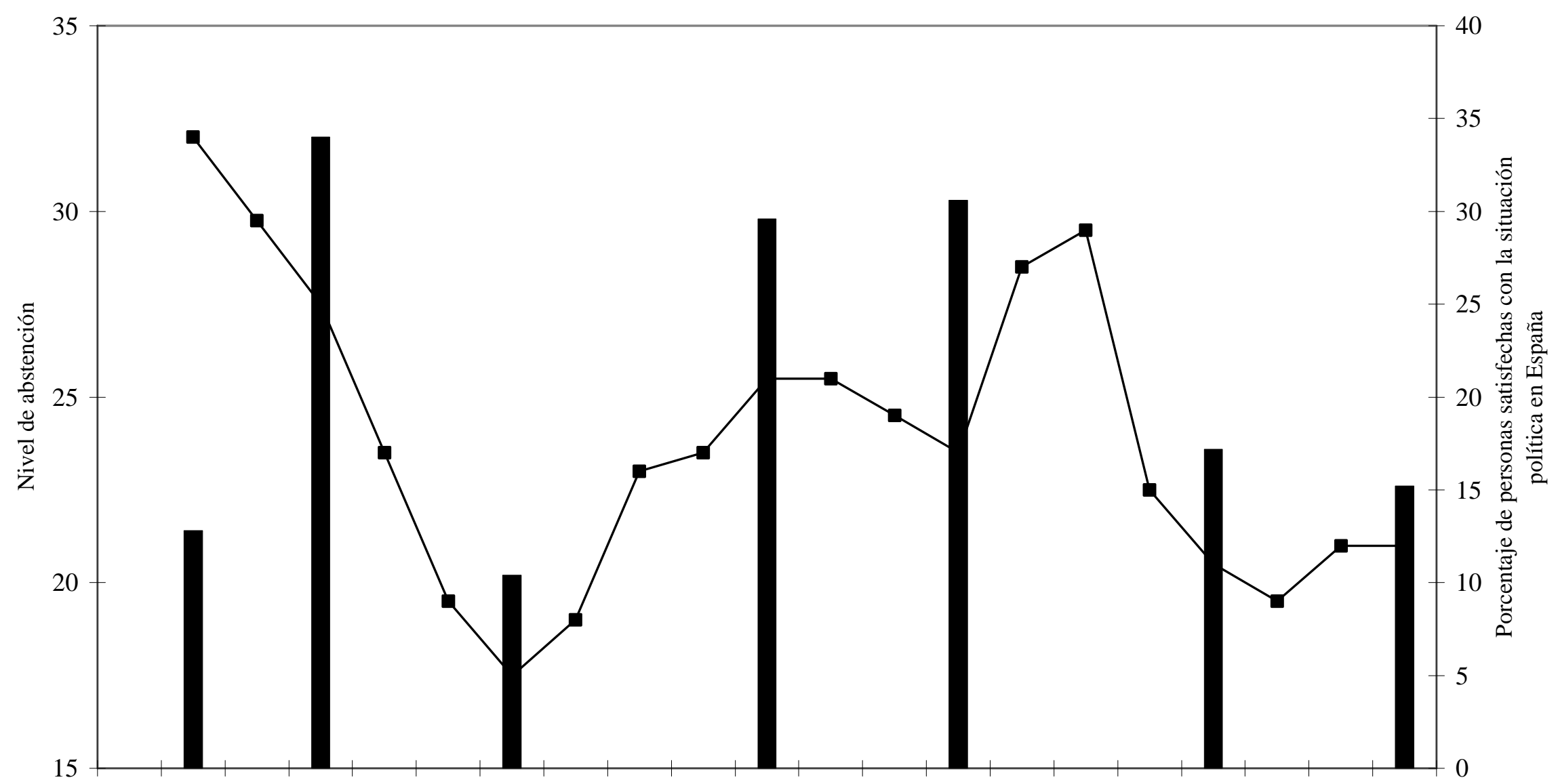

197619771978197919801981198219831984198519861987198819891990199119921993199419951996 Año 
Figura 3

Cambio en la participación electoral de 1979 a 1993

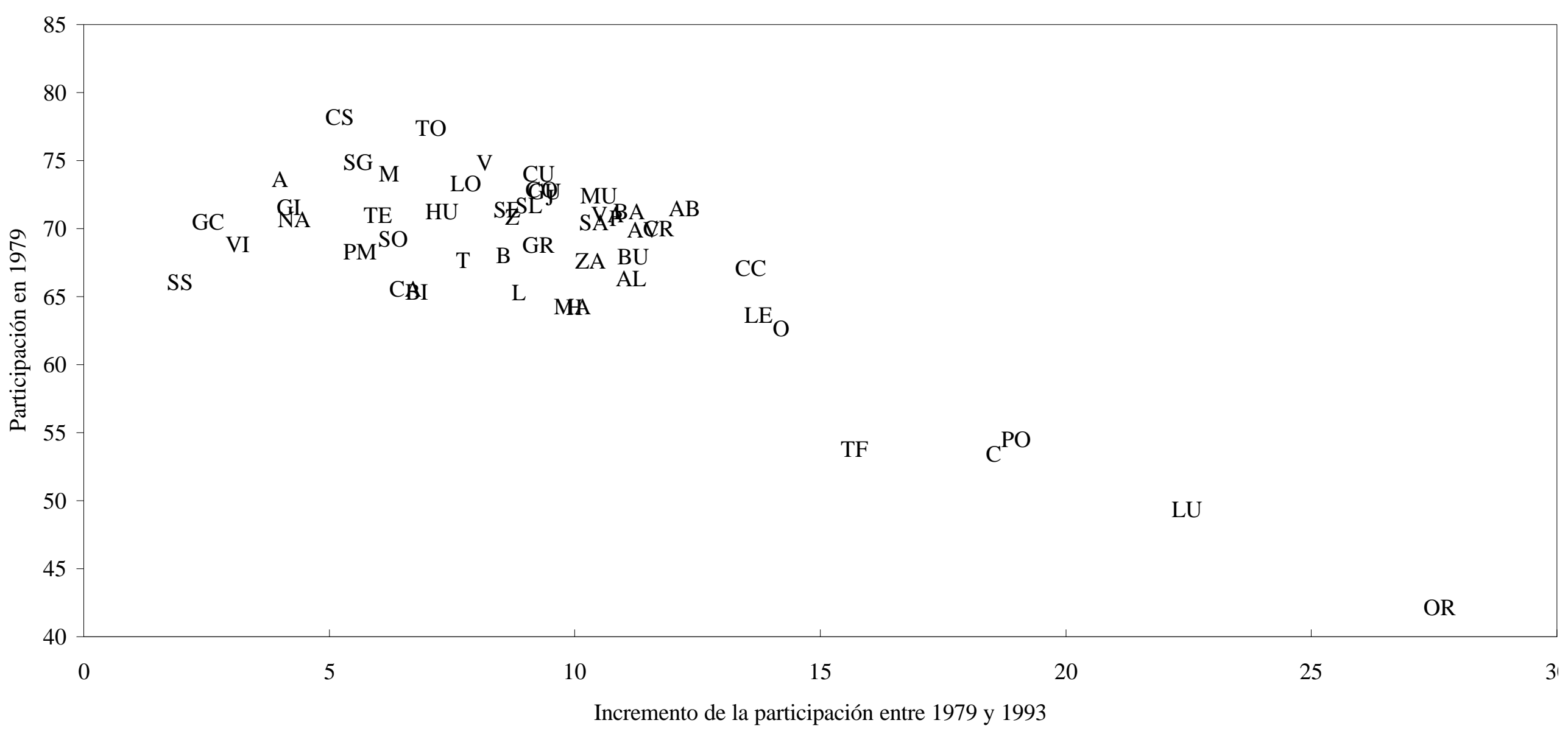


Figura 4

El efecto de la edad del elector sobre la decisión de votar

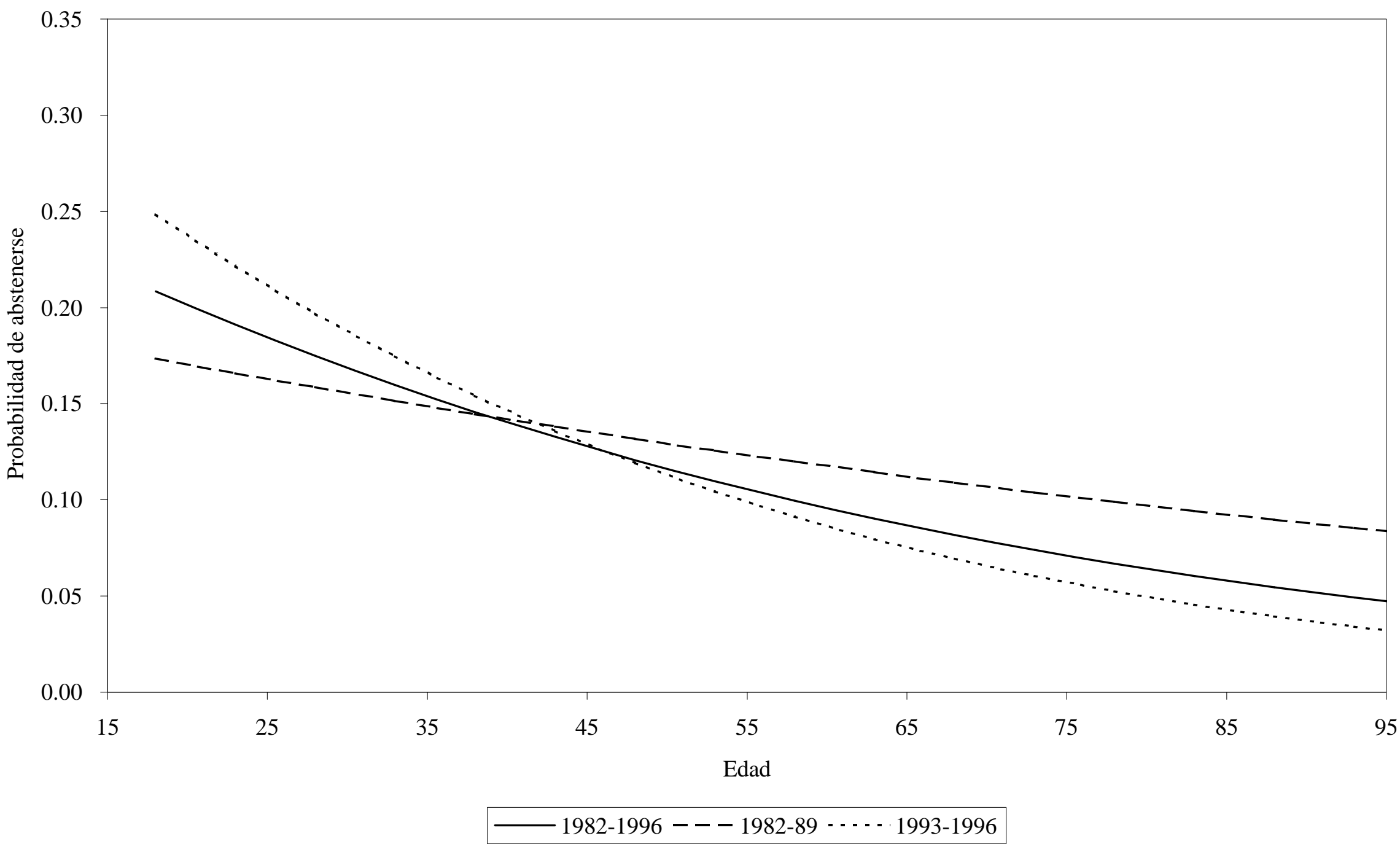


Figura 5

El efecto del nivel educativo sobre la decisión de votar

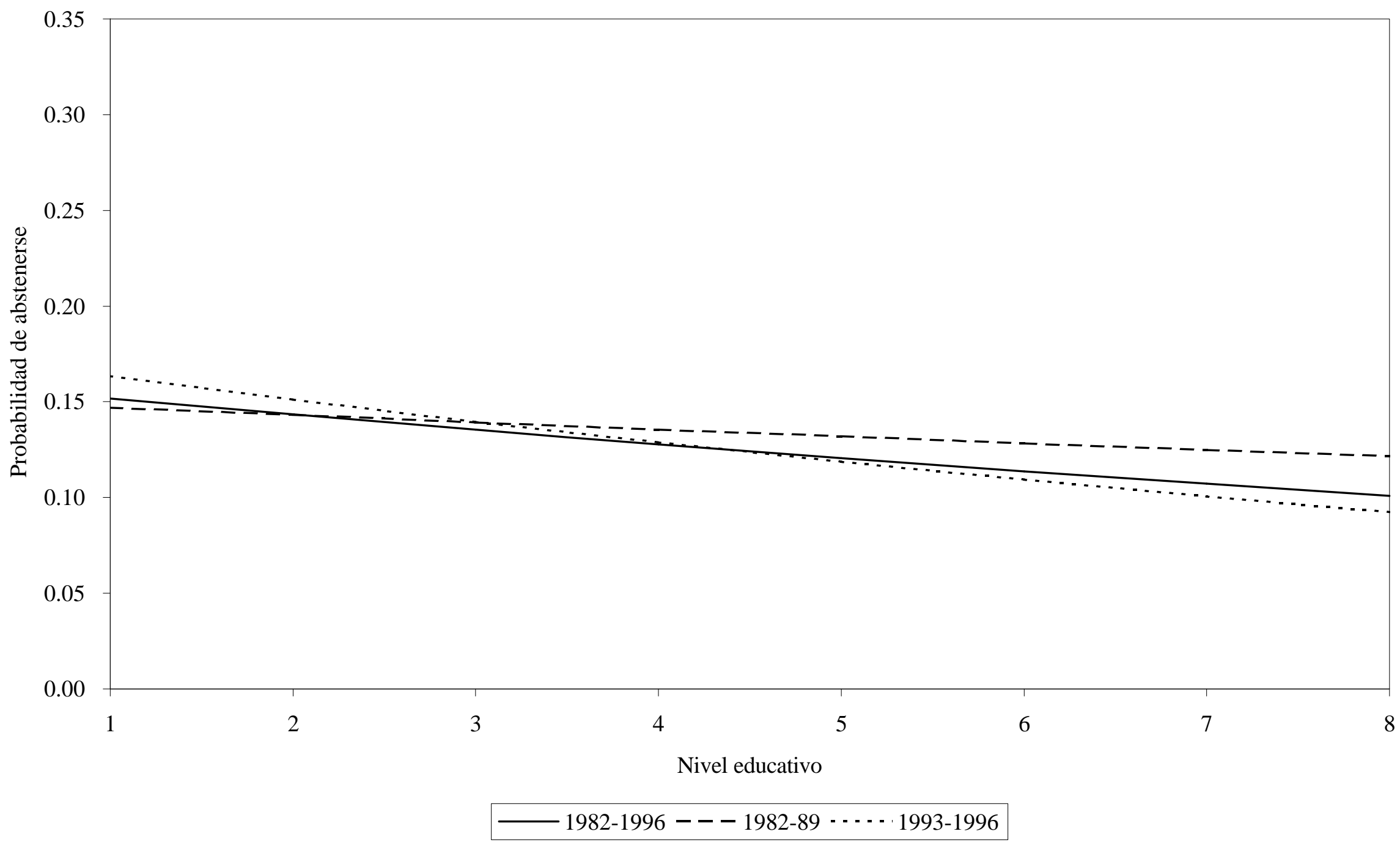


Figura 6

El efecto del tamaño de la población del elector sobre la decisión de votar

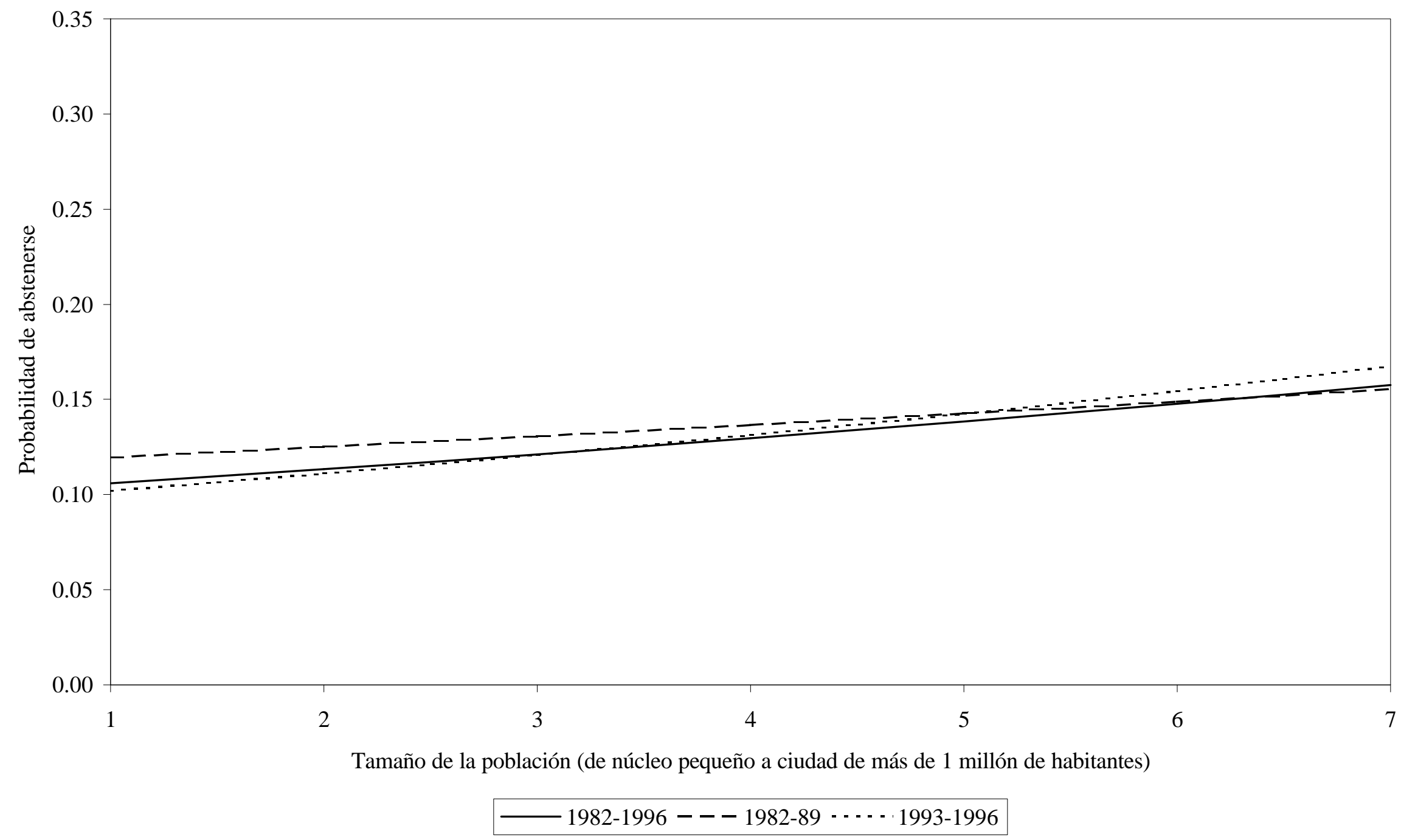


Figura 7

Grado de satisfacción a nivel nacional y decisión de votar

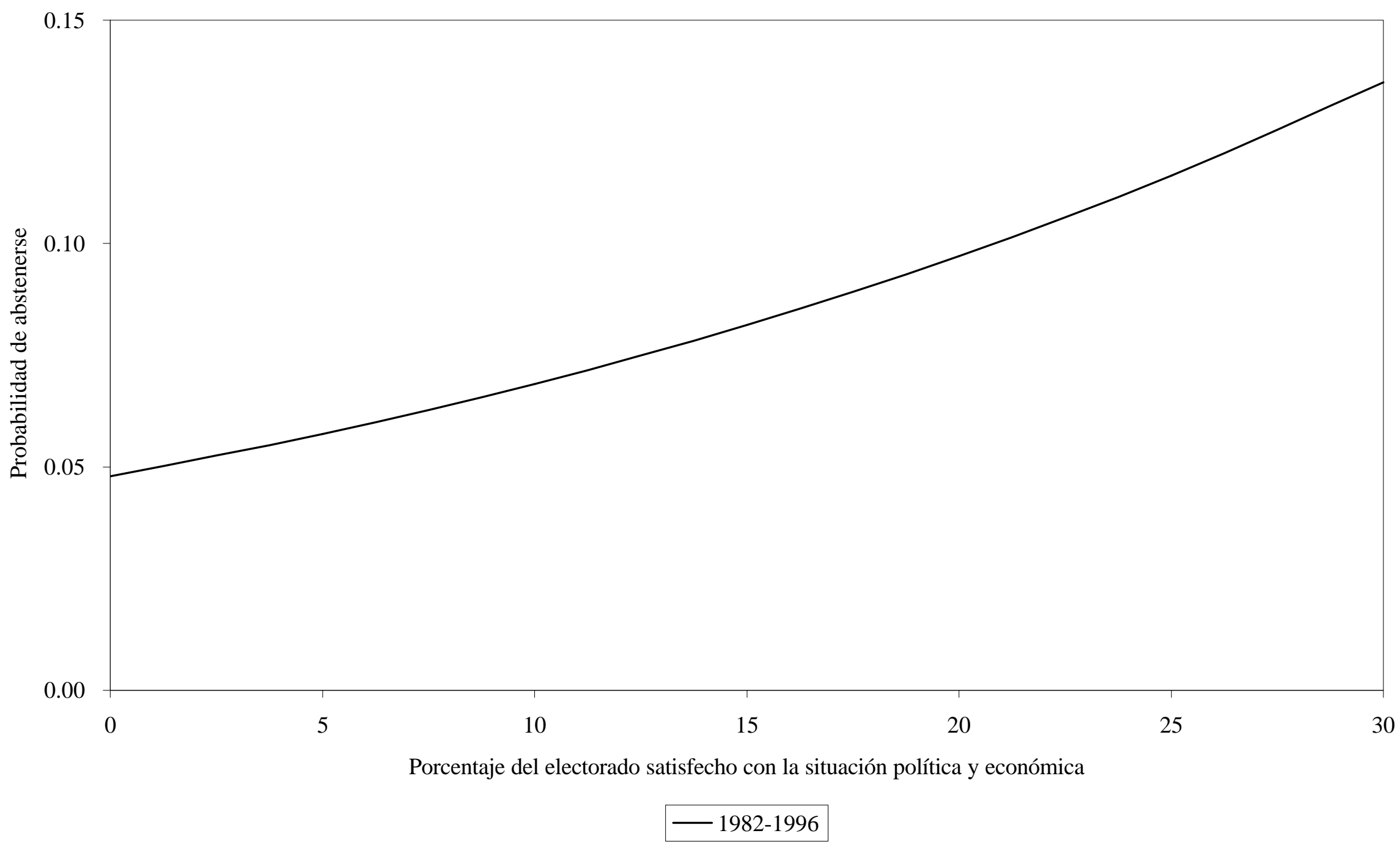


Figura 8

El impacto de la vida asociativa sobre la decisión de votar

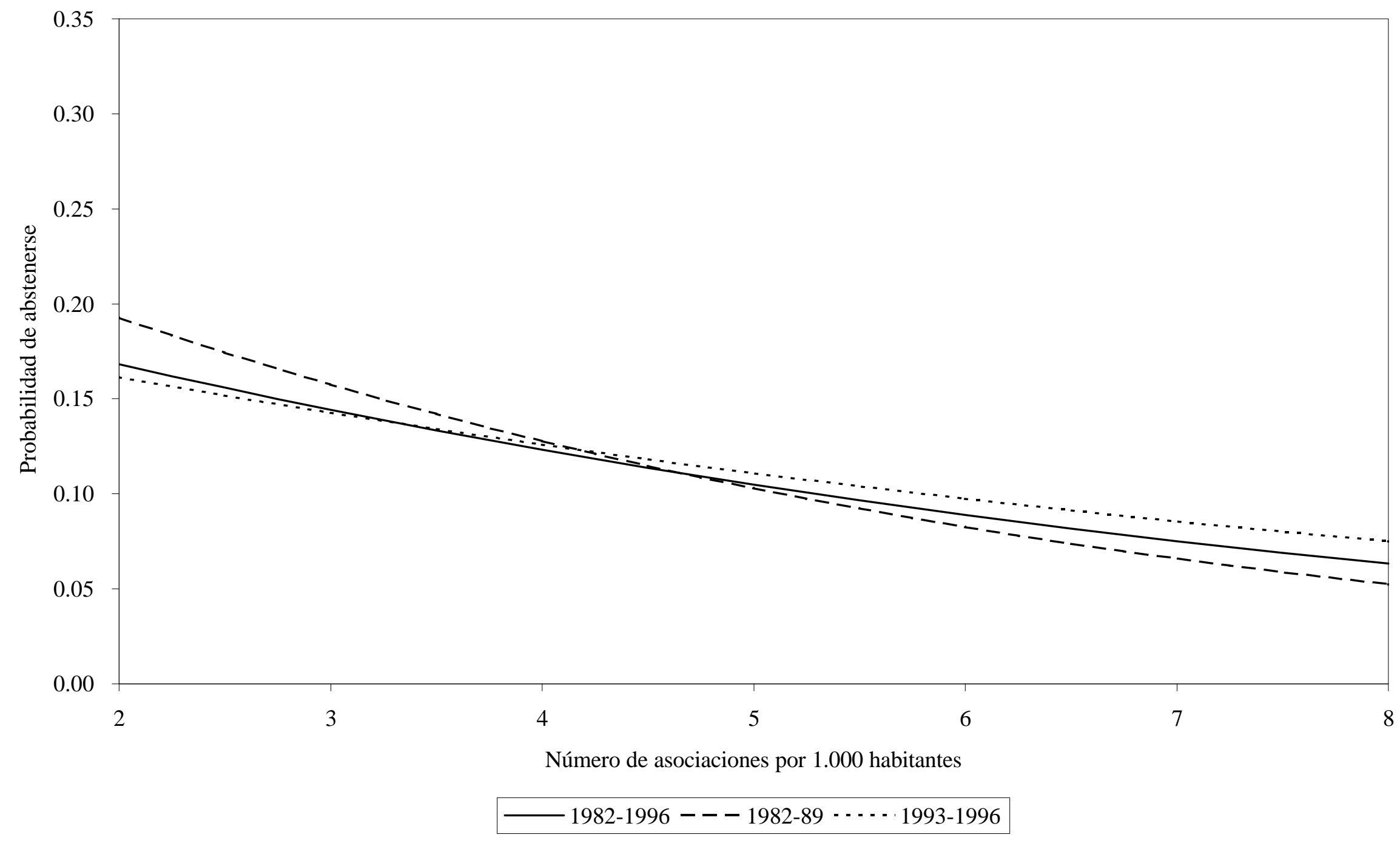


Figura 9

El efecto de la militancia política sobre la decisión de votar

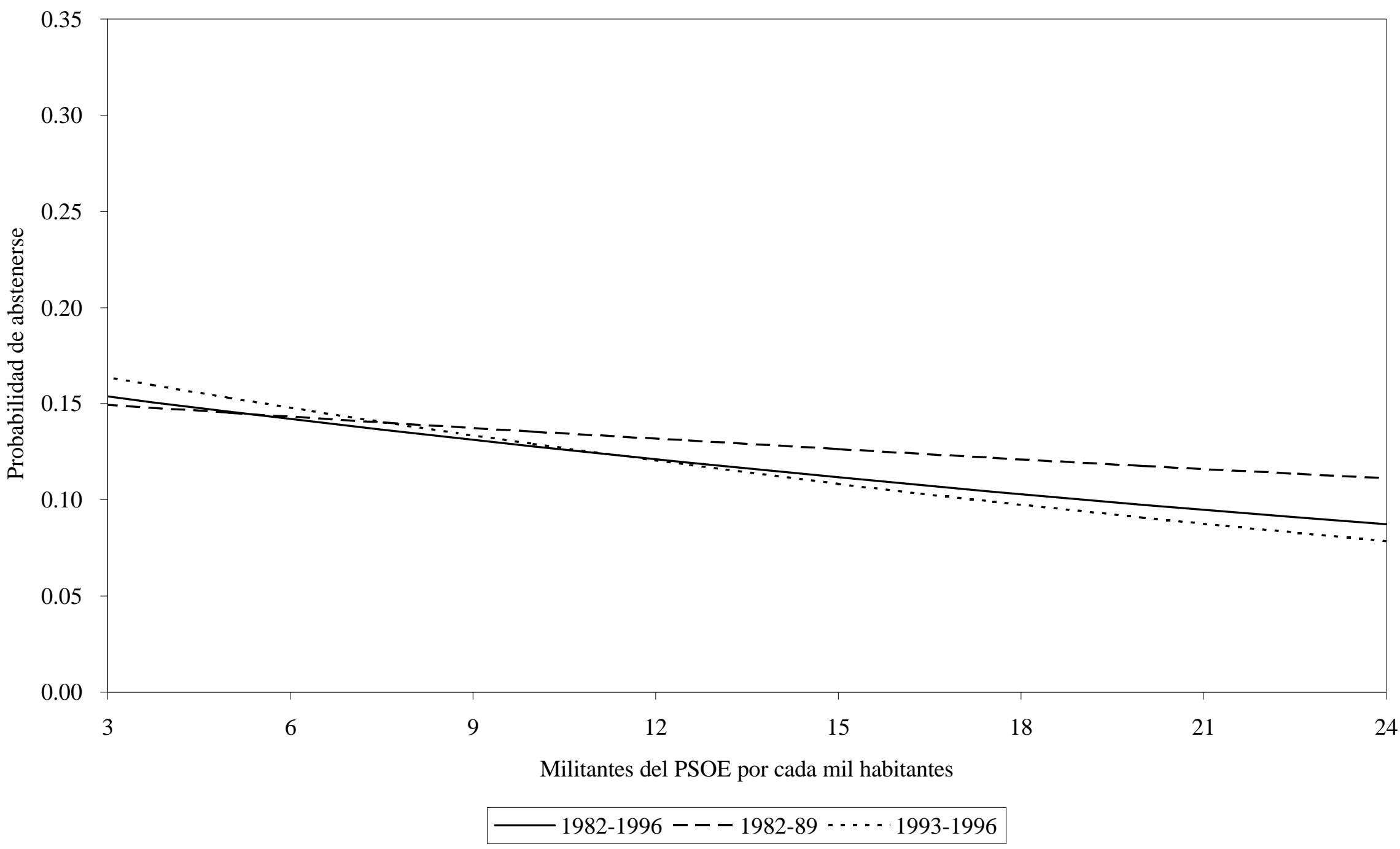


Figura 10

El efecto de la competitividad electoral sobre la decisión de votar

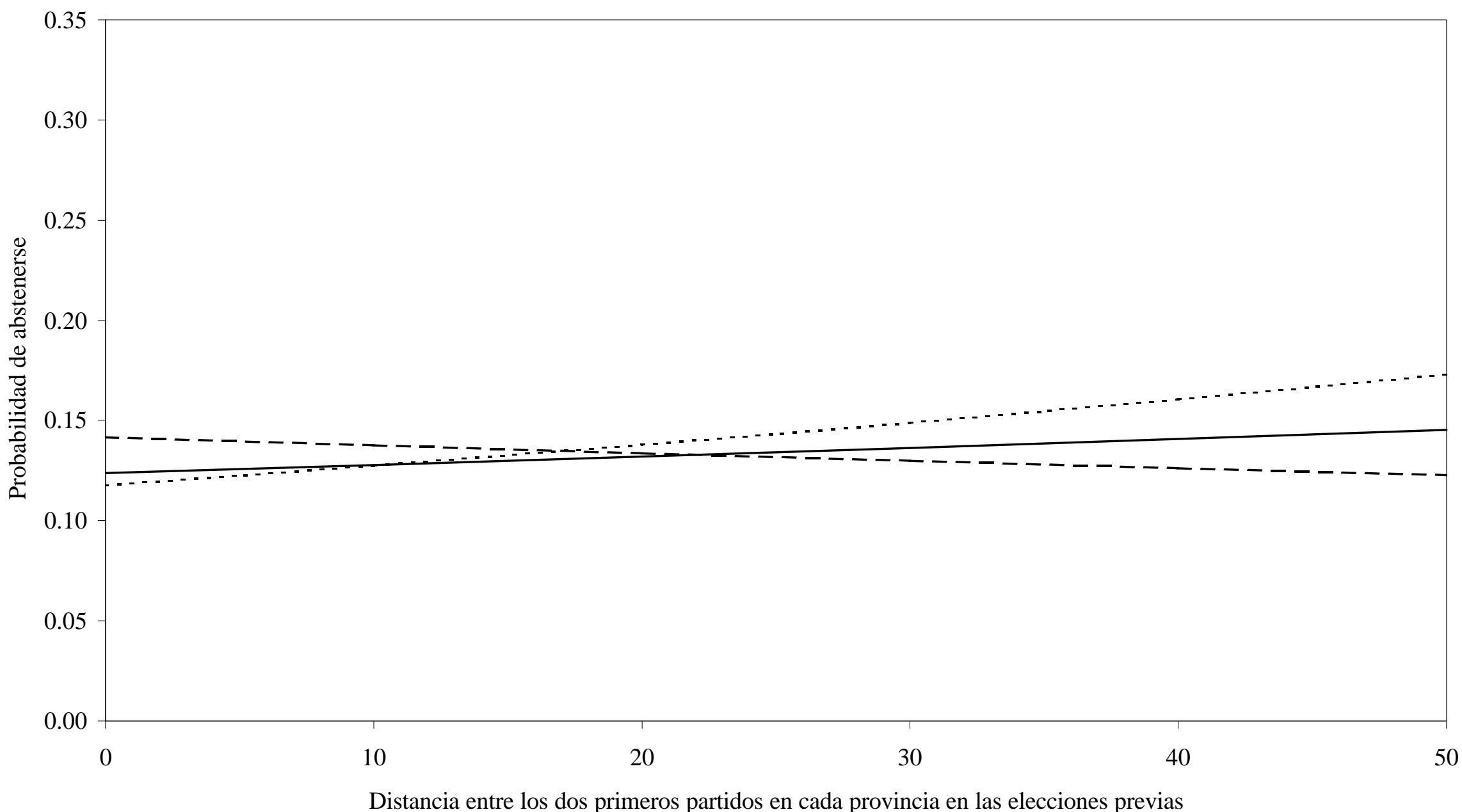

Distancia entre los dos primeros partidos en cada provincia en las elecciones previas

$1982-1996---1982-89 \cdots \cdots \cdot 1993-1996$ 
Figura 11

El efecto de la barrera electoral efectiva sobre la decisión de votar

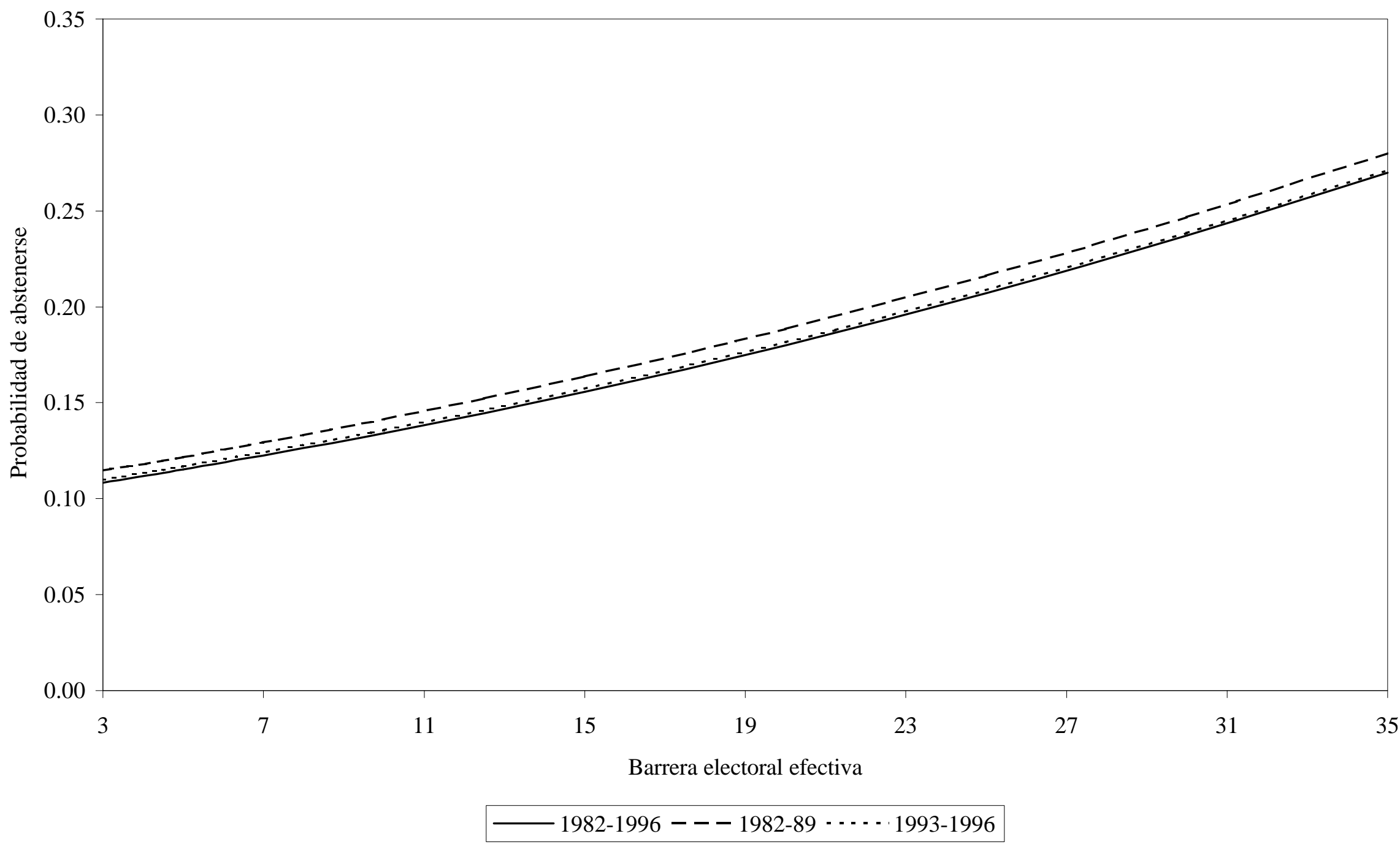


Figura 12

El efecto del interés individual por la campaña electoral sobre la decisión de votar

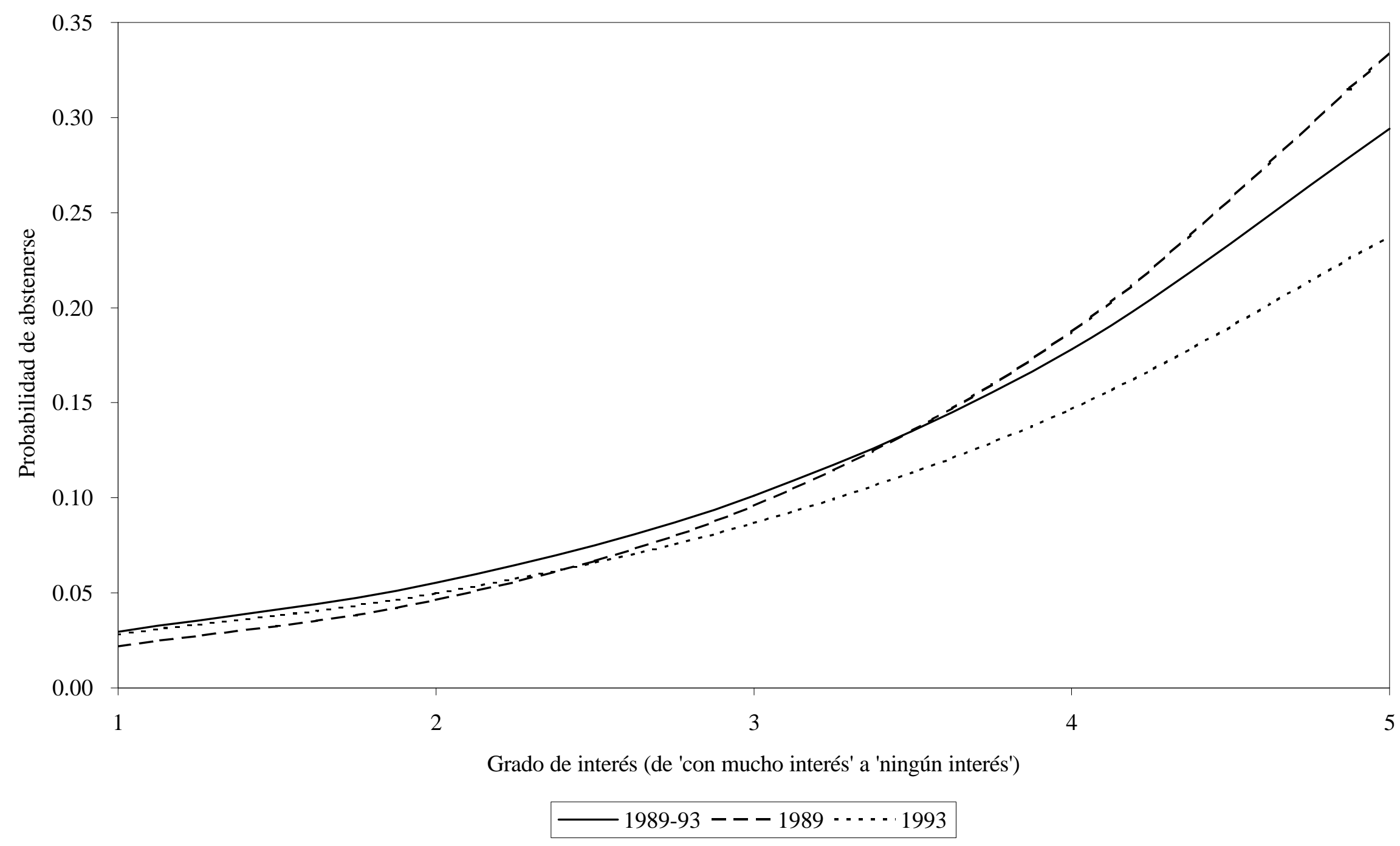


Figura 13

Indiferencia ideológica y decisión de votar

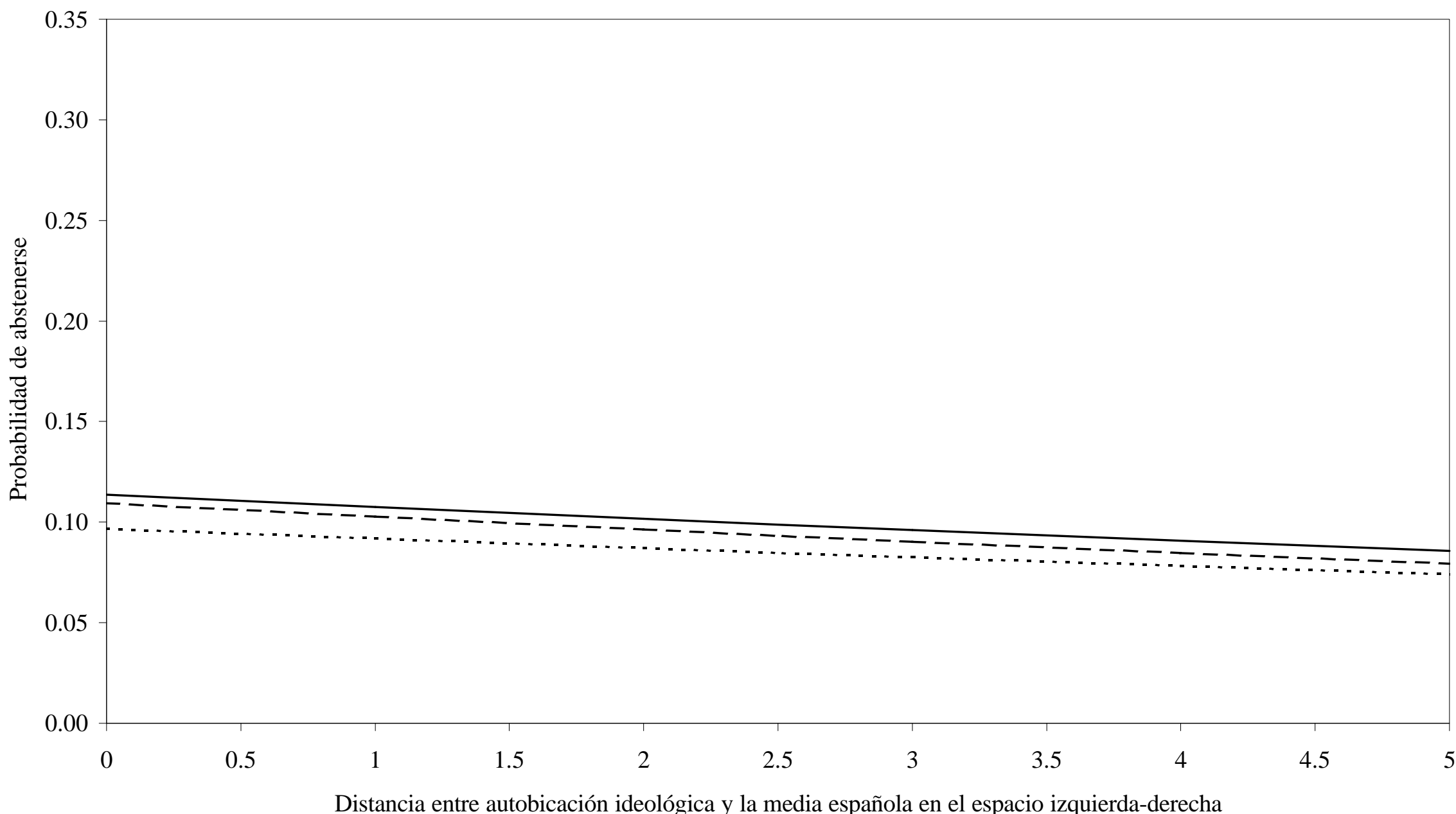

Distancia entre autobicación ideológica y la media española en el espacio izquierda-derecha 